\title{
ALTERAÇÃO METAMÓRFICO-HIDROTERMAL NOS DEPÓSITOS DE OURO TIPO- VEIO DE PORTO NACIONAL, TO, BRASIL: EVIDÊNCIAS DE QUÍMICA MINERAL E MICROESTRUTURAS NA ZONA DE CISALHAMENTO CACHIMBO
}

\author{
MARIA JOSÉ DE MESQUITA ${ }^{1}$, LEO AFRANIO HARTMANN ${ }^{2}$, WILLIAM SAFTON FYFE ${ }^{3}$, \\ JEFERSON DE LIMA PICANÇO ${ }^{1} \&$ ALICE BONATO DE CASTRO ${ }^{4}$.
}

\begin{abstract}
Resumo A Zona de Cisalhamento Cachimbo (ZCC) faz parte do Lineamento Transbrasiliano, Província Tectônica Tocantins, centro-oeste do Brasil. A ZCC é responsável pela formação de milonitos e filonitos que alojam um complexo sistema de veios de quartzo, mineralizados a ouro. As rochas encaixantes são metagranitos de fácies anfibolito superior, com quartzo, ortoclásio, plagioclásio, mica branca, e clorita. A partir de evidências de química mineral e microestruturas, foi possível caracterizar as condições físicoquímicas do cisalhamento e metamorfismo-hidrotermal da ZCC. O primeiro estágio é marcado por uma intensa alteração filica, que gera milonitos com feldspato, quartzo, muscovita-ferrifengita, clorita, monazita e zircão. A partição do metamorfismo-hidrotermal gera dois tipos de filonitos: (a) fengita-granada filonito, com a paragênese quartzo-granada-clorita-muscovita/fengita-turmalina e, (b) paragonita-estaurolita filonito com quartzo-clorita-paragonita-estaurolita-turmalinatgranadatcalcita. Os paragonita-estaurolita filonitos caracterizam sítios relativamente mais aluminosos e os fengita-granada filonitos caracterizam sítios relativamente mais magnesianos. A orientação de inclusões de turmalina em porfiroblastos de estaurolita caracteriza os porfiroblastos como sin-cinemáticos a foliação principal dos filonitos. A formação de estaurolita e granada indica condições similares de fácies anfibolito, zona da estaurolita para o metamorfismo-hidrotermal. Os paragonita-estaurolita filonito e os fengita-granada filonito evoluem para o fengita filonito, com uma paragênese mais simples de muscovita-fengita, clorita magnesiana pirita e calcopirita. Vênulas de calcita \pm pirita \pm calcopirita e vênulas monominerálicas de pirita cortam os filonitos. A zona potencialmente mineralizada é marcada pelo grafita filonito, com a paragênese quartzo-grafita-pirita \pm ouro. O grafita filonito é aloja os veios de quartzo auríferos, que tem a paragênese quartzo-piritatcalcopirita \pm grafita \pm ouro. $O$ grafita tem alta cristalinidade e espectro coincidente com o de condições de fácies anfibolito, zona da estaurolita, evidenciando que as condições metamórfico-hidrotermais se mantiveram ao longo da evolução da ZCC. A fugacidade de oxigênio estimada para a formação do grafita é baixa que, juntamente com a formação de pirita, caracterizam um ambiente redutor para as transformações mineralógicas finais na ZCC e a precipitação do ouro.
\end{abstract}

Palavras-chave: ouro, alteração metamórfico-hidrotermal, estaurolita hidrotermal, cristalinidade do grafita, Zona de Cisalhamento Cachimbo.

\begin{abstract}
METAMORPHIC-HYDROTHERMAL ALTERATION AT THE VEIN-TYPE GOLD DEPOSIT OF PORTO NACIONAL, TO, BRAZIL: MINERAL CHEMISTRY AND MICROSTRUCTURAL EVIDENCES IN THE CACHIMBO SHEAR ZONE. The Cachimbo shear zone (CSZ) is part of the Transbrasiliano lineament (LTB), Tocantins tectonic province, in West-Central Brazil. The CSZ has mylonites and phyllonites, which host gold deposits of quartz vein-type. The host rocks are upper amphibolite facies metagranites of the Manduca suite (MS) composed of quartz, orthoclase, plagioclase, white mica, and Fe chlorite. Based on mineral chemistry and microstructures, it is possible to characterize the physico-chemical conditions of shear deformation and metamorphichydrothermal alteration in the CSZ. The first stage of shearing is marked by phyllic alteration and generation of early myllonites composed of muscovite-ferriphengite, chlorite, monazite and zircon. The metamorphic-hydrothermal events generate two distinct phyllonites: (a) phengite-garnet phyllonite, with an assemblage of quartz-garnet-chlorite-muscovite/phengite-tourmaline; and (b) paragonite-staurolite phyllonite, with an assemblage of quartz- staurolite-chlorite-paragonite-tourmaline \pm calcite \pm garnet. The paragonite-staurolite phyllonite occurs in more aluminous sites and the phengite-garnet phyllonite in more magnesian sites. Tourmaline inclusions in staurolite porphyroblasts sub-parallel to the main foliation characterize the porphyroblasts generated synkinematic to the phyllonite foliation. Garnet and staurolite indicate amphibolite facies conditions in the staurolite zone for the hydrothermalmetamorphism. The paragonite-staurolite phyllonite and the phengite-garnet phyllonite evolve to the phengite phyllonite, with a simpler assemblage of chlorite-muscovite/phengite-pyrite and chalcopyrite. Calcitetpyritetchalcopyrite veinlets and monomyneralic pyrite veinlets cross-cut the phyllonites. Graphite phyllonite marks the potential mineralized zone, with an assemblage of quartz-graphite-pyrite \pm gold. Graphite phyllonites host the mineralized quartz vein system with an assemblage of quartz \pm graphite \pm pyrite \pm chalcopyrite \pm gold. The high crystallinity of graphite is similar to the spectrum of amphibolite facies, staurolite zone conditions. It seems to demonstrate the persistence of hydrothermal- metamorphic conditions during the CSZ evolution. The low oxygen fugacity for the graphite formation, together with pyrite mineral, indicates a reduced environment for gold precipitation.
\end{abstract}

Keywords: gold, metamorphic-hydrothermal alteration, hydrothermal staurolite, high crystallinity of graphite, Cachimbo Shear Zone.

INTRODUÇão A região de Porto Nacional está inserida na porção setentrional da Província Estrutural do Tocantins, Cinturão Paraguai-Araguaia (Hasui et al. 1984; Hasui \& Sena Costa, 1990, Marini et al. 1984, Hasui \& Haralyi 1985). A mineralização de ouro na região está condicionada a um grande sistema de cisalhamento, correlacionado ao Lineamento Transbrasiliano
(LTB - Schobbenhaus Filho et al., 1975). O desenvolvimento do LTB, na região de Porto Nacional, está tectonicamente relacionado aos eventos finais de um processo de colisão continental entre os Crátons São Francisco e Amazônico. Os dados geocronológicos existentes para ao LTB são controversos, e apontam, conforme Sena Costa et al. (1988) para idades mais antigas que 
$1873 \pm 25 \mathrm{Ma}$, ou, conforme Cordani et al. (2000), ao Ciclo Orogênico Brasiliano. Nesta região o LTB é caracterizado por diversas zonas de cisalhamento de direção NE-SW, onde existem mais de cinqüenta garimpos e cavas de Bandeirantes ao longo de aproximadamente $140 \mathrm{~km}$. As ocorrências auríferas estão associadas a grandes sistemas de veios de quartzo. As lavras são a céu aberto e os dados locais informais apontam para um teor médio de 2 a $5 \mathrm{~g} /$ ton de ouro. O minério mais rico nos veios pode chegar a $20 \mathrm{~g} /$ ton em média.

A circulação de fluidos em zonas de cisalhamento é um fenômeno amplamente reconhecido, responsável pela hidratação de rochas e pela deposição de elementos de interesse econômico, como o ouro. A extensa formação de filonitos e veios de quartzo, durante o período de atividade de uma zona de cisalhamento, evidencia que a pressão de fluidos nesta zona excedeu a pressão litostática, como observado por Sibson (1990), Cox et al. (1990), Hippert (1998), Godard \& Evans (1995), entre outros.

A microtectônica é ferramenta fundamental em estudos de granitos deformados, uma vez que o sistema quartzo-feldspático não é adequado à formação de minerais-índices. O grau metamórfico de granitos metamorfizados tem sido amplamente estudado com base em microestruturas de deformação e petrotrama (Johnson et al. 2003; Hirth \& Tullis, 1992; Tullis \& Yund 1985 e 1987, Mesquita \& Fernandes 1991).

O presente estudo apresenta dados integrados de química mineral e de análise de microestruturas de deformação em minerais. Estes dados são aplicados aos metagranitos, milonitos e filonitos hospedeiros do depósito tipo-veio encaixado na Zona de Cisalhamento Cachimbo, região de Porto Nacional, estado do Tocantins. O objetivo aqui é estabelecer uma correlação entre o incremento da deformação cisalhante, que gera milonitos, filonitos e veios de quartzo a partir de um protólito granítico, e a evolução das paragêneses metamórfico-hidrotermais em uma zona de cisalhamento de fácies anfibolito.

CONTEXTO GEOLÓGiCO Na região de Porto Nacional foram identificadas oito associações litotectônicas principais (cf. Mesquita 1996, Cunha 1996 e Gottardo 1996) e ilustrado na Figura 1. O Complexo Porto Nacional, a Suíte Manduca e o Grupo Natividade são polideformados e constituem o embasamento da área. Essas rochas são intrudidas pela Suíte Matança (SMç), a qual possui características de magmatismo sintectônico ao sistema transcorrente do LTB, segundo Barradas et al. (1992) e Gottardo (1996). A Suíte Ipueiras (SI) é intrusiva nas seqüências anteriores. Os contatos entre as unidades CPN, SM, GN e SMç são por zonas de cisalhamento. As coberturas sedimentares presentes na área são representadas pela formação Monte do Carmo, pelas formações Pimenteiras e Serra Grande (Bacia do Parnaíba) e pelos depósitos aluvionares recentes do rio Tocantins.

O Complexo Porto Nacional (CPN) ocorre como uma faixa alongada segundo a direção NE-SW. É composto por metatonalitos, metabasitos e gnaisses quartzo-feldspáticos, metamorfisados na fácies granulito, com idade do metamorfismo determinada pelo método $\mathrm{Pb} / \mathrm{Pb}$ em zircão em $2.1 \mathrm{Ga}$ (Gorayeb, 1996; Gorayeb et al. 2000). Faixas irregulares de milonitos e filonitos que afetam o CPN, anteriormente descritas como metassedimentos da Formação Morro do Aquiles (Senna Costa et al. 1984), alojam veios de quartzo auríferos.

A Suíte Manduca (SM), anteriormente incluída no CPN, é aqui individualizada (Mesquita, 1996; Cunha, 1996 e Gottardo, 1996) e leva o nome do córrego homônimo, onde se apresenta melhor caracterizada (Fig. 1). Compreende vários tipos de metagranitóides e ortognaisses de fácies anfibolito superior, metamorfismo definido pelas microestruturas em feldspato e quartzo. A suíte faz parte possivelmente do Arco Magmático de Goiás, definido por Pimentel \& Fuck (1992)

A Zona de Cisalhamento Cachimbo desenvolve-se sobre as rochas da SM e gera extensas faixas de filonitos e milonitos com veios de quartzo mineralizados a ouro, tema central do presente trabalho.

O Grupo Natividade (GN) é uma seqüência polideformada de quartzitos, filitos, quartzitos conglomeráticos e rochas metabásicas, com exposição descontínua ao longo da área. São estreitas faixas de orientação NE-SW, intrudidas pela SI e recobertas pela Bacia do Parnaíba e Formação Monte do Carmo.

A foliação $S_{n}$, observada no CPN, é um bandamento gnáissico caracterizado pela alternância de bandas máficas e félsicas. $\mathrm{O}$ bandamento é variavelmente transposto por uma foliação anastomosada, plano axial $\left(S_{n+1}\right)$, presente nas unidades CPN, SM e GN. As relações geométricas e espaciais entre a $S_{n}$ e a $S_{n+1}$ mostram que ambas as superficies foram paralelizadas durante o evento deformacional $D_{n+1}$. O sistema de cisalhamento transcorrente, ao qual pertence à Zona de cisalhamento Cachimbo, caracteriza o evento $D_{\text {, }}$

A Suite Matança (SMç) ocorre como uma faixa NE-SW a noroeste da cidade de Porto Nacional (Fig. 1) e é constituída por granitóides porfiríticos a equigranulares, extremamente foliados e cortados por diques de diorito, aplito e pegmatito. Os metagranitóides da Suite Matança são sin-cinemáticos ao sistema de cisalhamento transcorrente (evento $\mathrm{D}_{n+2}$ ), conforme Barradas et al. (1992). Os autores apresentam uma isócrona $\mathrm{Rb} / \mathrm{Sr}$ (rocha total) com idade de $510 \pm 15 \mathrm{Ma}$ (RI 0,7128), interpretada como idade da suíte.

A Suíte Ipueiras (SI) é definida originalmente por Bezerra et al. (1981) como Associação plutono-vulcânica de Ipueiras e é equivalente a Suíte Lageado de Senna Costa et al. (1984). É constituída por um conjunto de intrusões de forma elíptica, orientadas segundo as direções gerais N-S e NE-SW. Gottardo (1996) individualizou os corpos graníticos do Carmo (GC), Aroeira (GA), Itaboca (GI) e Jacaré (GJ, Fig. 1). Possui contatos intrusivos com o CPN, SM e GN, sendo recoberto a NE da área pelos sedimentos da bacia do Parnaíba. A SI é composta por monzogranitos e sienogranitos isótropos, diques básicos, gabros e sub-vulcânicas ácidas (Fig. 1). Localmente, exibem deformação de natureza rúptil a rúptil-dúctil e são intrusões tardi-cinemáticas ao sistema de cisalhamento transcorrente (evento $\mathrm{D}_{\mathrm{n}+2}$ ). A SI apresenta alteração hidrotermal, principalmente no limite dos corpos graníticos, associada a veios de quartzo mineralizados. As idades geocronológicas disponíveis são: $1873 \pm 25 \mathrm{Ma}$ (Rb-Sr em rocha total, Senna Costa \& Hasui, 1988), $1986 \pm 49$ $\mathrm{Ma}(\mathrm{Pb}-\mathrm{Pb}$ em rocha total no Granito do Carmo, Barradas et al. 1992), $2024 \pm 103 \mathrm{Ma}(\mathrm{Pb}-\mathrm{Pb}$ em rocha total nas vulcânicas ácidas, Barradas et al. 1992).

A Zona de Cisalhamento Cachimbo O sistema de cisalhamento aqui descrito é relacionado genericamente ao Lineamento Transbrasiliano (Schobbehaus Filho et al. 1975). As principais estruturas de primeira ordem deste sistema, individualizadas na área, são a Zona de Cisalhamento Cachimbo (ZCC), Mutum (ZCM), Conceição (ZCCo) e Carmo (ZCCa - Fig.1).

A ZCC é uma das estruturas que condiciona a mineralização de ouro tipo-veio da Província de Porto Nacional. É do tipo transcorrente a oblíqua, dúctil a rúptil-dúctil, com direção preferencial $030^{\circ}-210^{\circ}$ e sentido de movimento levógiro. Esta zona tem no mínimo $80 \mathrm{~km}$ de extensão e ocorre próximo ou no contato inferido entre a Suíte Manduca e o Complexo Porto Nacional (Fig. 1). Na sua porção norte, é balizada por serras sustentadas pelas rochas do Grupo Natividade e, ao sul, a zona afeta e inflete a foliação pretérita $\left(\mathrm{S}_{\mathrm{n}+1}\right)$ do $\mathrm{GN}$.

A ZCC deforma e altera hidrotermalmente metagranitos da Suíte Manduca, formando uma faixa de 300 a $800 \mathrm{~m}$ de largura 


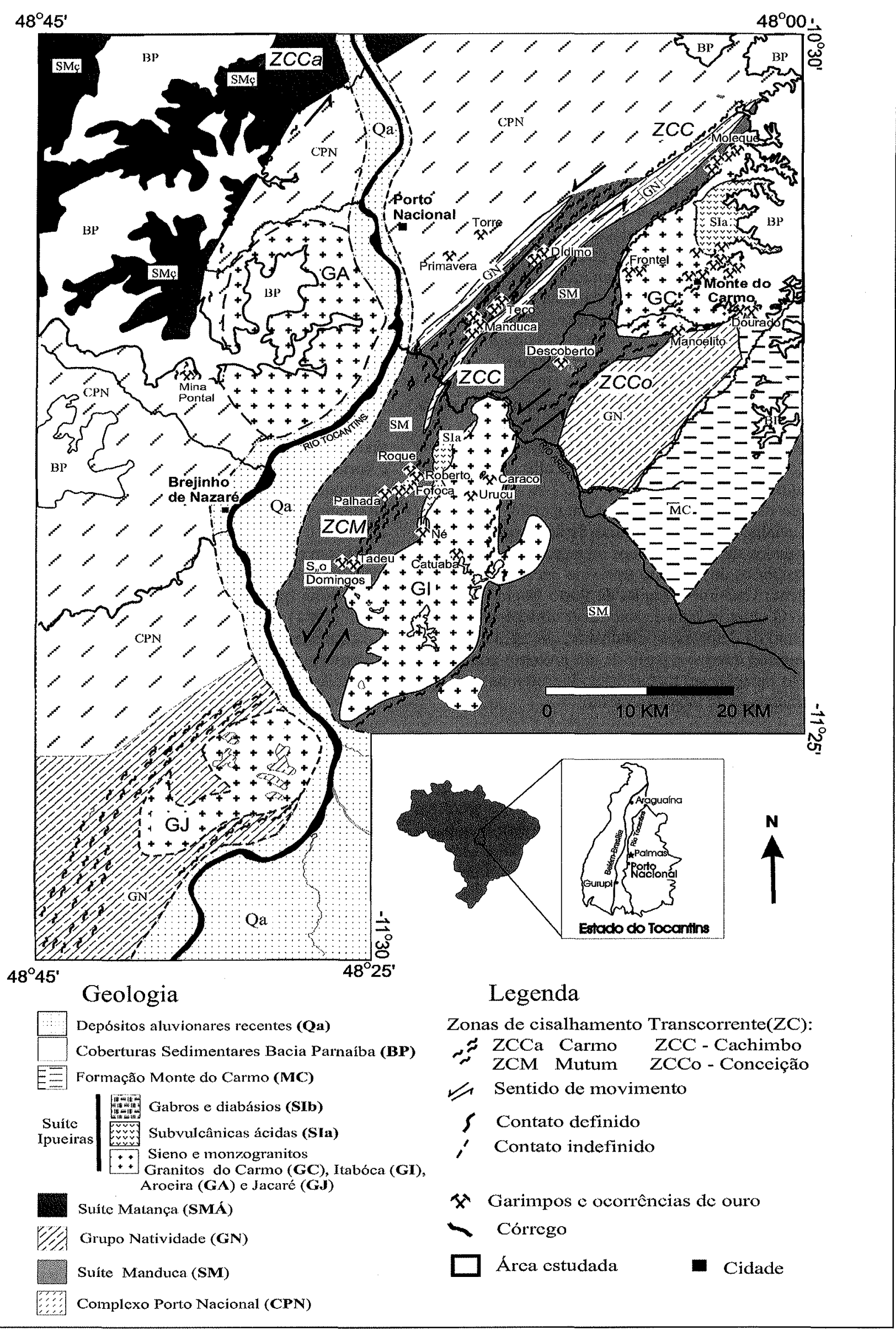

Figura 1-Mapa Geológico da Região de Porto Nacional, (TO), definido a partir de mapeamento litoestrutural em escala 1:100.000 pela primeira autora (Mesquita, 1996). Os principais garimpos da região estão indicados. 
composta pela alternância de milonitos e filonitos. A zona mineralizada é composta por grafita filonitos e complexos sistemas de veios de quartzo e ouro (Fig. 2).

A grande importância de se identificar às zonas de milonitos e filonitos na área, anteriormente confundidas com faixas de metassedimentos, advém do fato dessas rochas serem as principais hospedeiras de veios de quartzo mineralizados a ouro. Estes depósitos podem ser incluídos no modelo de Depósitos de Ouro Orogênico, conforme classificação de Groves et al. (1998). Tal fato pode reorientar futuras campanhas prospectivas na região.

PETROGRAFIA As rochas aqui descritas seguem uma seqüência evolutiva a partir de um protólito granítico-gnáissico, previamente deformado e metamorfizado, para rochas de cisalhamento e, finalmente, para a zona mineralizada. Esta evolução é descrita na Zona de Cisalhamento Cachimbo e ocorre devido à combinação dos processos de deformação cisalhante transcorrente $\left(D_{n+2}\right)$ e de alteração metamórfico-hidrotermal.

Protólito: Metagranitos A Suíte Manduca é composta, na área de estudo, por metassienogranitos a metagranodioritos de granulação média, com uma grande variação textural devido à heterogeneidade dos eventos de deformação sucessivos sofridos pela rocha. A principal estrutura pré-transcorrência é um bandamento gnáissico descontínuo $\left(\mathrm{S}_{\mathrm{n}+1}\right)$, de natureza milonítica, marcado por niveis de filossilicatos e níveis de quartzo em fitas (ribbon) e porfiroclastos de K-feldspato (Fig. 3A). A associação mineralógica principal é quartzo, K-feldspato, oligoclásio, mica branca (muscovita-ferrimuscovita) e uma mistura clorita férrica/ mica branca, pseudomorfos de biotita provavelmente. Os minerais acessórios são zircão, rutilo, monazita, apatita, hematita e ilmenita. As feições de recristalização dinâmica em feldspato e quartzo corroboram o metamorfismo de fácies anfibolito superior a granulito do evento deformacional $\mathrm{D}_{n+1}$, definido no Complexo Porto Nacional (Gorayeb, 1996). Os grãos reliquiares maiores de feldspato contém subgrãos relativamente grandes com desorientação de até $5^{\circ}$. A ocorrência de subgrãos com esta morfologia é compatível com temperaturas muito elevadas de deformação, já que implicam na ativação de vários sistemas de deslizamento, só possível em feldspato acima de $550^{\circ} \mathrm{C}$ (Fitz Gerald \& Stunitz, 1993, Bitencourt, 1996). O quartzo apresenta subgrãos do tipo tabuleiro de xadrez (chessboard texture), caracterizados por subgrãos prismáticos e basais no mesmo cristal, indicando temperaturas acima de $600^{\circ} \mathrm{C}$ (Khrull, 1996).

O metagranito apresenta uma pronunciada foliação milonítica nordeste $\left(\mathrm{S}_{\mathrm{n}+2}\right)$, que corta a $\mathrm{S}_{n+1} . \mathrm{A} \mathrm{S}_{\mathrm{n}+2}$, precoce à formação dos filonitos na ZCC, é marcada por porfiroblastos de muscovita tipo peixe (fish) e feldspato amendoado (augen).Uma forte lineação de estiramento mineral é marcada por fitas de quartzo e muscovita. A deformação $D_{n+2}$ é caracterizada por uma segunda associação mineralógica de quartzo, microclínio, albita, mica branca II (muscovita-ferrifengita) e clorita férrica II. A foliação milonítica evolui para faixas métricas de filonitos e milonitos que preservam pods dos metagranitos. Vênulas centimétricas de quartzo e albita cortam os metagranitos.

Rochas de cisalhamento: milonitos, filonitos e veios de quartzo As rochas geradas na Zona de Cisalhamento Cachimbo compreendem: milonito precoce, fengita-granada filonito, paragonita-estaurolita filonito e fengita filonito. A zona mineralizada é composta pelo grafita filonito e por veios de quartzo.

Os milonitos precoces caracterizam-se pela formação indiscriminada de mica branca, podendo formar porfiroblastos. Porfiroclastos de albita são circundados por matriz de mica branca, clorita, quartzo e trilhas de monazita e zircão.

Os filonitos são compostos genericamente pela alternância de bandas de mica branca, de clorita, de uma mistura cloritamica branca e de quartzo (Fig. 3B). Dois tipos de filonitos foram identificados de acordo com a variedade de mica branca presente: fengita-granada filonito e paragonita-estaurolita filonito. As principais paragêneses e variações mineralógicas descritas para ambos os litotipos estão listadas na tabela 1. Estes dois tipos de filonitos, com o aumento da intensidade de deformação e alteração hidrotermal, gradam para o fengita filonito, o qual apresenta uma associação mineralógica mais simples, à base de muscovita-fengita, clorita e quartzo (tabela 1). O aparecimento de níveis centimétricos de grafita e pirita, no fengita filonito, marca o início da zona mineralizada, a qual mede aproximadamente 17 $\mathrm{m}$. Os níveis de grafita tornam-se mais freqüentes e coalescem formando o grafita filonito (Figs. 3C e 7B). Os filossilicatos e carbonato são parcialmente substituídos por material grafitoso disseminado, vênulas de quartzo, pirita e ouro.

Os veios de quartzo são cinza escuros a claros, devido a traços de grafita, e apresentam forte lineação de estiramento mineral (book texture) e bandamento interno, marcado por filmes de muscovita e grafita. Apresentam larguras desde $20 \mathrm{~cm}$ até $5 \mathrm{~m}$ e centenas de metros de extensão. Podem ser classificados, quanto ao seu posicionamento estrutural na Zona de Cisalhamento Cachimbo, conforme Hodgson (1989), como veios de cisalhamento central, veios de cisalhamento oblíquos e veios de extensão, estes últimos bem menos freqüentes (Fig.2).

CARACTERÍSTICAS PETROGRÁFICAS E QUÍMICA DOS MINERAIS As análises quantitativas de química mineral foram realizadas na microssonda eletrônica JEOL JXA8600 , no Departamento de Ciências da Terra, University of Western Ontario (UWO), Canadá. O grau de desordem do grafita foi medido por microespectroscopia Raman, realizada no Departamento de Química da University of Windsor, Windsor, Canadá, e os espectros foram coletados em um espectrômetro Ramanor U-1000. Foram realizadas contagens modais em lâminas delgadas de cerca de 2000 pontos por lâmina, com o uso de um contador acoplado ao microscópio petrográfico. A contagem modal foi realizada como apoio ao estudo de balanço de massa dos metagranitos para os milonitos e filonitos (cf. Mesquita, 1996; Mexias et al. 1997) e os resultados estão reunidos na tabela 1.

Quartzo, plagioclásio e feldspato potássico apresentam reduções percentuais consideráveis, enquanto a mica branca e a clorita apresentam aumento progressivo. Comparando-se o protólito metagranítico com o fengita-filonito mais deformado, tem-se a seguinte variação nas percentagens modais: quartzo varia de $32,9 \%$ para $23 \%$; plagioclásio $23,9 \%$ para $0,6 \%$; K-feldspato $17,9 \%$ para $0 \%$; mica branca $16,3 \%$ para $45,1 \%$; clorita $2,7 \%$ para $29,6 \%$; carbonato $0 \%$ para $3,7 \%$; turmalina $0 \%$ para $5,2 \%$ e sulfetos $0 \%$ para $4,4 \%$.

As mudanças químicas e microestruturais dos minerais nas diferentes zonas de alteração metamórfico-hidrotermal na ZCC refletem as flutuações de temperatura, tensão cisalhante, pressão e composição de fluidos,. Pelo fato do metamorfismo-hidrotermal ocorrer em zonas de cisalhamento e ser controlado pela deformação, é importante que a geoquímica seja estudada conjuntamente com a geologia estrutural.

Feldspatos e quartzo Em feldspato potássico, foram realizadas 14 análises em 12 grãos de cinco amostras diferentes. Em plagioclásio, foram realizadas 33 análises em 25 grãos de seis amostras diferentes.

Nos metagranitos, o alongamento de quartzo e feldspato marca a foliação milonítica e ocorre de duas maneiras principais, como (a), grãos reliquiares com deformação intracristalina intensa e, como (b), grãos recristalizados, produto de recristalização dinâmica dos grãos reliquiares (Fig. 3A). Os grãos reli- 


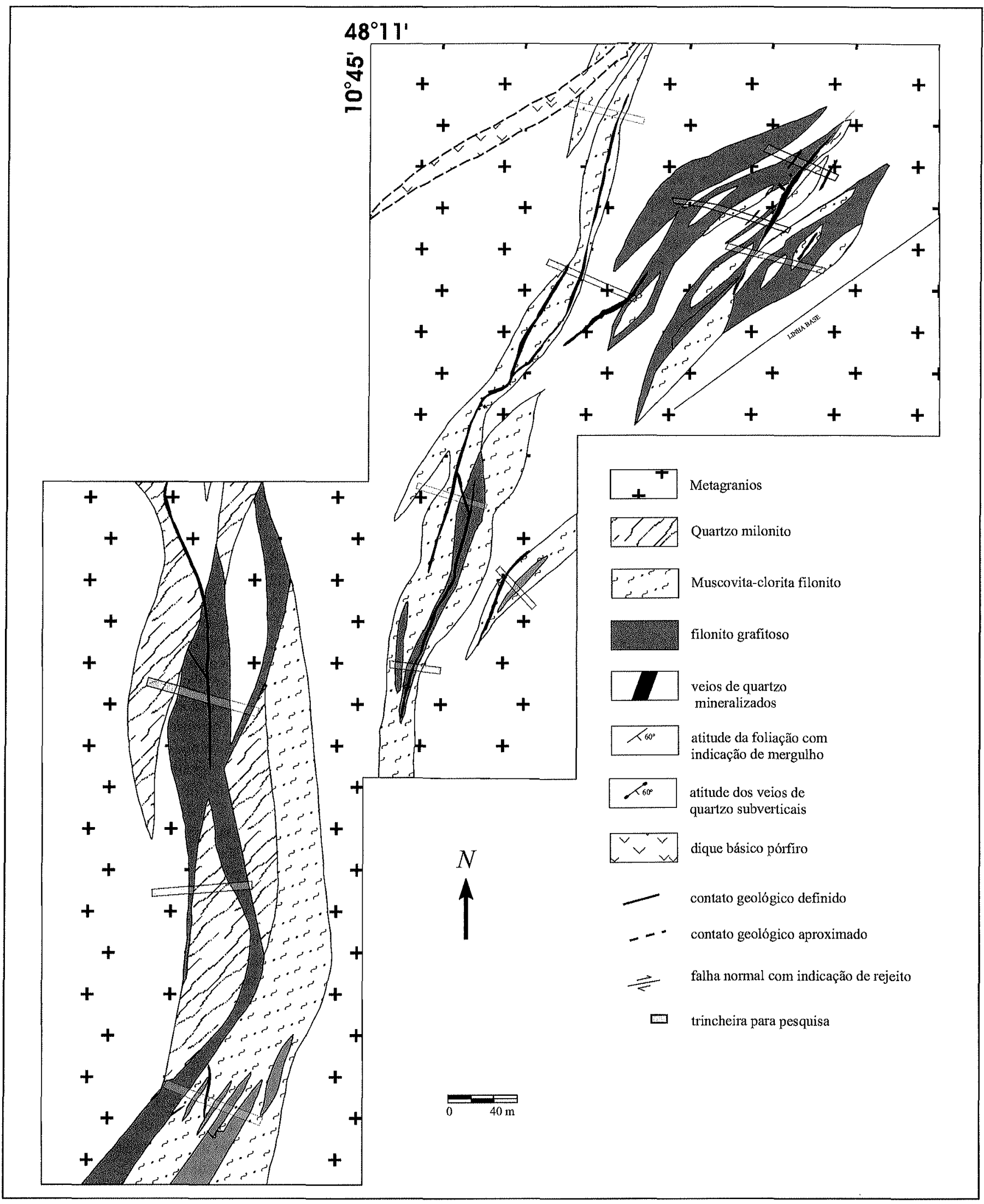

Figura 2 - Esboço Geológico do Alvo Dydimo, indicado na Figura 1, na área de estudo. Distribuição das rochas de cisalhamento e veios mineralizados da Zona de Cisalhamento Cachimbo, confeccionado pela primeira autora a partir da análise estrutural de 10 trincheiras e mapeamento geológico em escala 1:500.

quiares de feldspato potássico são classificados como ortoclásio $\left(\mathrm{Or}_{93-95}\right)$. Contudo, os grãos recristalizados apresentam geminação característica de microclínio.
Os grãos reliquiares de plagioclásio são deformados, com subgrãos e grãos recristalizados. Os limites dos grãos são irregulares, com mantos de recristalização. Apresentam variação com- 
Tabela 1- Principais paragêneses minerais das diversas rochas estudadas na Zona de Cisalhamento Cachimbo: (Feg-grn) fengitagranada, (Prg-est) paragonita-estaurolita, (Feg) fengita, (gra) grafita, (qz) quartzo. No protólito granitico foram separadas as paragêneses I e $2(\mathrm{Pg} I)$ e $(\mathrm{Pg} I I)$, respectivamente. A percentagem dos minerais é baseada em análise petrográfica modal.

escala de espessura de traços referente a percentagem modal do mineral

Intensidade de deformação/ hidrotermalismo

\begin{tabular}{|c|c|c|c|c|c|c|c|c|}
\hline \multirow{2}{*}{ Minerais } & \multicolumn{2}{|c|}{ Protólito Granítico } & \multicolumn{4}{|c|}{ Rochas de cisalhamento } & \multicolumn{2}{|c|}{ Zona de minério } \\
\hline & Pg I & Pg II & $\begin{array}{l}\text { Milonito } \\
\text { precoce }\end{array}$ & $\begin{array}{l}\text { Feg-grn } \\
\text { filonito }\end{array}$ & $\begin{array}{l}\text { Prg-est } \\
\text { filonito }\end{array}$ & $\begin{array}{l}\text { Feg } \\
\text { filonito }\end{array}$ & $\begin{array}{l}\text { graf } \\
\text { filonito }\end{array}$ & $\begin{array}{l}\text { Veios } \\
q z\end{array}$ \\
\hline \multicolumn{9}{|l|}{ Quartzo } \\
\hline \multicolumn{9}{|l|}{ K-feldspato } \\
\hline \multicolumn{9}{|l|}{ Oligoclásio } \\
\hline \multicolumn{9}{|l|}{ Albita } \\
\hline \multicolumn{9}{|l|}{ Clorita } \\
\hline \multicolumn{9}{|l|}{ Muscovita } \\
\hline \multicolumn{9}{|l|}{ Paragonita } \\
\hline \multicolumn{9}{|l|}{ Zircão } \\
\hline \multicolumn{9}{|l|}{ Apatita } \\
\hline \multicolumn{9}{|l|}{ Ilmenita } \\
\hline \multicolumn{9}{|l|}{ Rutilo } \\
\hline \multicolumn{9}{|l|}{ Monazita } \\
\hline \multicolumn{9}{|l|}{ Hematita } \\
\hline \multicolumn{9}{|l|}{ Granada } \\
\hline \multicolumn{9}{|l|}{ Estaurolita } \\
\hline \multicolumn{9}{|l|}{ Turmalina } \\
\hline \multicolumn{9}{|l|}{ Calcita } \\
\hline \multicolumn{9}{|l|}{ Pirita } \\
\hline \multicolumn{9}{|l|}{ Calcopirita } \\
\hline Grafite & & & & & & & & \\
\hline Ouro & & & & & & & & \\
\hline
\end{tabular}

posicional, com núcleo de oligoclásio $\left(A n_{\text {, }}\right)$ e borda de albita $(\mathrm{An})$. Os grãos recristalizados de plagioclásio são poligonais e sem 1' deformação intracristalina. Apresentam composição albítica $(\mathrm{An}$,$) , similar às bordas dos grãos reliquiares. Muitos grãos$ recristallizados têm bordas de quartzo. Observa-se que quanto maior a deformação intracristalina, menor o conteúdo de cálcio dos grãos reliquiares, sugerindo uma remoção seletiva de cálcio e, posteriormente, de sódio, nos grãos recristalizados com a deformação. O mecanismo principal que explica esta variação de composição é a difusão, igualmente observado por Gomes (1991) na deformação do Granito Arroio Moinho, Escudo Sulriograndense.

O plagioclásio e K-feldspato são restritos aos primeiros estágios de milonitização, transformando-se em mica branca nos filonitos.

O quartzo ocorre nos filonitos com textura em fitas ou em vênulas, cortando a foliação.

Os veios de quartzo auríferos são caracteristicamente cinza a cinza escuros, devido à presença de grafita. Nestes veios, o quartzo exibe feições que indicam múltiplos estágios de precipitação e recristalização. A natureza das microestruturas em quart- zo também varia com a posição dentro do veio. Nas porções centrais dos veios, o quartzo apresenta grãos equigranulares. A deformação neste caso parece ter sido dominada por processos de recuperação-recristalização dinâmica, como indicado por microestruturas intracristalinas como extinção ondulante, lamelas de deformação e subgrãos.

Nas margens dos veios, o quartzo apresenta uma maior variedade de microestruturas como: (a) quartzo recristalizado; (b) grãos reliquiares de quartzo quase sem deformação com um manto de recristalização e (c) formação indiscriminada de matriz criptocristalina de quartzo. Essas microestruturas caracterizam processos de dissolução e recristalização dinâmica. Gradientes extremos de stress são inferidos às margens dos veios, próprios da ocorrência de fragmentos de rocha encaixante e anisotropias como contato veio-rocha. Vênulas de quartzo brancas, sem grafita, cortam os veios de quartzo e apresentam texturas do tipo crack-seal, com evidências de várias gerações de abertura e fechamento. Nos grãos reliquiares de quartzo dos veios mineralizados ocorrem inclusões fluidas do tipo $\mathrm{H}_{2} \mathrm{O}-\mathrm{CO}_{2}-\mathrm{CH}_{4}$ de baixa salinidade $(<3$ peso $\%$ de $\mathrm{NaCl})$ com temperaturas acima de $350^{\circ} \mathrm{C}$. Nos grãos recristalizados, associados à mineraliza- 

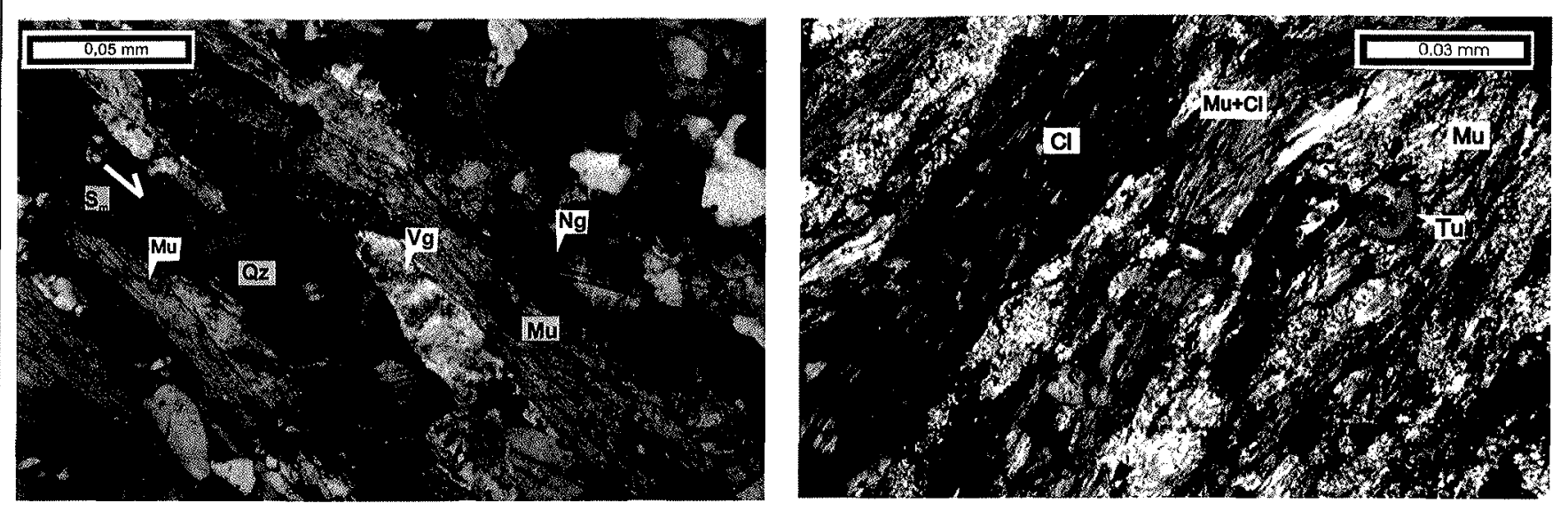

Figura 3-Fotomicrografias em luz polarizada (LP), (a) intercalação de níveis quartzo-feldspáticos e micáceos definindo a foliação milonítica $\left(S_{n+2}\right)$ nos metagranitos: $(V g)$ grãos reliquiares de feldspato potássico, $(\mathrm{Ng})$ grãos recristalizados de feldspato potássico, (Mu) muscovita I, (Qz) quartzo. (b) bandamento hidrotermal nos filonitos. Bandas de clorita (C l), bandas de uma mistura clorita+muscovita $(\mathrm{Mu}+\mathrm{Cl})$ e bandas de muscovita (Mu), detalhe para grão de turmalina (Tu). (c) Grafita filonito. Lentes de quartzo (Qz) envoltas por muscovita (Mu) e clorita (Cl). Grafita (Gr) substitui os filossilicatos ao longo da foliação.

ção, ocorrem inclusões fluidas do tipo $\mathrm{H}_{2} \mathrm{O}-\mathrm{CO}_{2}$, de mais baixa temperatura $<300^{\circ} \mathrm{C}$ e salinidade variável entre 3 e 15 peso $\%$ de $\mathrm{NaCl}$. (Mesquita et al. a, em preparação).

Mica Branca A mica branca é um mineral índice tanto nos metagranitos encaixantes quanto nos milonitos e filonitos da $\mathrm{ZCC}$, pois as variedades texturais e químicas marcam os diferentes estágios de interação fluido-rocha e deformação. Foram realizadas 68 análises em 47 grãos de mica branca, provenientes de 11 amostras diferentes.

Nos metagranitos, duas gerações de mica branca são observadas: porfiroclastos de mica branca I e mica branca II na matriz. Os porfiroclastos de mica branca I marcam a foliação $S_{n+2}$ (Fig. 3A). Apresentam deformação intracristalina, como kink bands, e limites irregulares com sombra de pressão preenchida por quartzo, mica branca II e microclínio. A composição química obtida para a mica branca I é intermediária entre os membros muscovita e ferri-muscovita, segundo a classificação de Guidotti (1987, Fig. 4), com os valores mais elevados de $\mathrm{Al}^{\mathrm{IV}}$.

A mica branca II ocorre como produto da recristalização dinâmica da mica branca I. Apresenta uma zonação composicional irregular, com porções do grão com composição química semelhante à mica branca I e porções tendendo ao componente final ferri-fengita (Fig. 4). Os grãos não zonados apresentam composição química intermediária entre os termos zonados. As porções ferri-fengíticas da mica branca II, quando comparadas com a mica branca I, são mais enriquecidas em Si e $\mathrm{Fe}_{(t)}+\mathrm{Mg}$ e empobrecidas em $\mathrm{Al}_{(t)}$ (tabela 2).

Conforme a classificação de Velde (1985, Fig. 5A e B), a mica branca tanto no protólito quanto nos milonitos e filonitos, situa-se na linha de solução sólida muscovita-fengita. Na figura $5 \mathrm{~A}$ observa-se a composição mais fengítica da mica branca II dos metagranitos.

No milonito precoce, caracterizado por intensa alteração fílica, ocorre a formação indiscriminada de mica branca, gerando uma matriz criptocristalina, que envolve restos de feldspatos e bandas de quartzo. Em locais de sombra de pressão, onde a tensão cisalhante é menos intensa, ocorrem porfiroblastos de mica branca, os quais apresentam uma zonação composicional entre muscovita e ferri-fengita, semelhante à mica branca II nos metagranitos, porém com valores bem elevados de $\mathrm{Fe}_{(\mathrm{t})}$ (Fig. 4). Nos milonitos, algumas análises de mica branca apresentam compo-

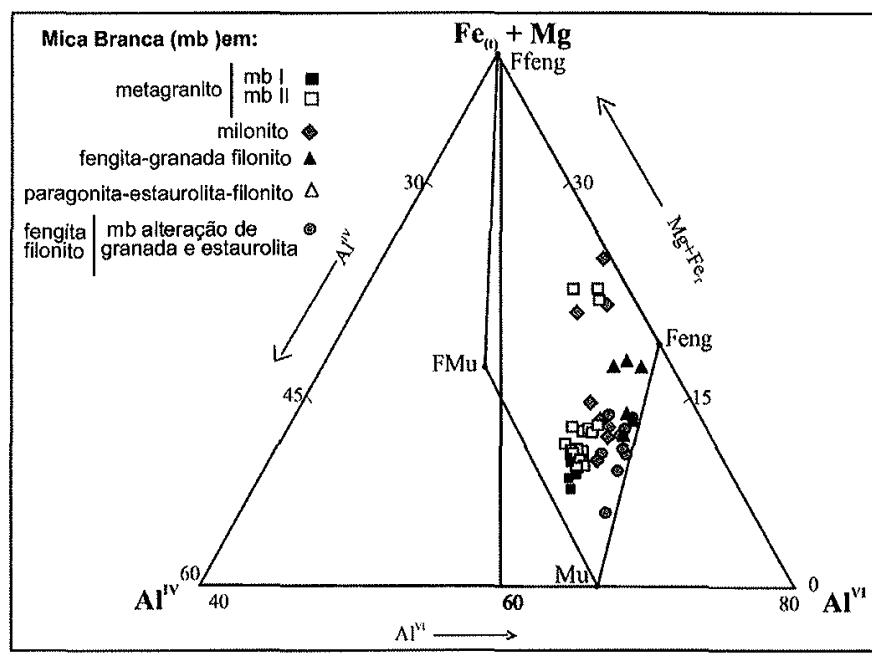

Figura 4 - Mica Branca da Zona de Cisalhamento Cachimbo no Sistema $A l^{(i v)}-A l^{\left({ }^{(i)}\right.}-F e_{(t)}+M g$, conforme classificação de Guidotti, (1987). FMu - ferri-muscovita, Mu - muscovita, Feng - fengita, Ffeng - ferri-fengita. A paragonita não está representada no diagrama.

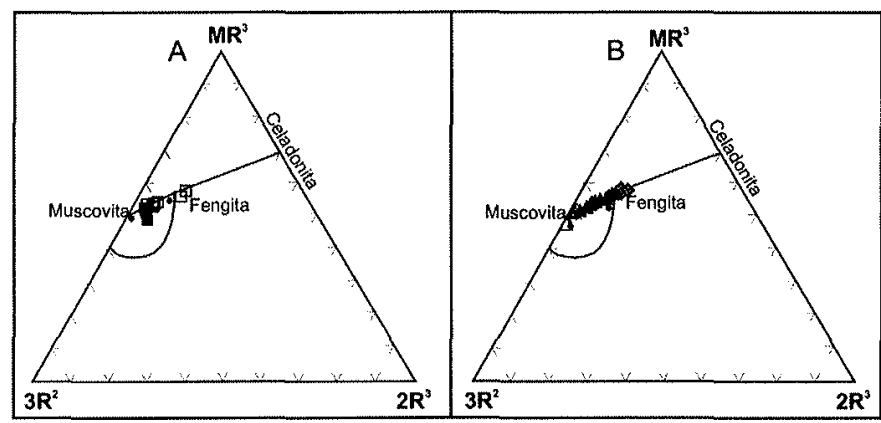

Figura 5-Representação quimiográfica da mica branca na Zona de Cisalhamento Cachimbo conforme diagrama $M R^{3}-2 R^{3}-3 R^{2}$, Velde (1985). $M R^{3}=N a+K+2 C a ; 2 R^{3}=\left(A l_{(i)}\right)-M R^{3} / 2 ; 3 R^{2}=$ $(\mathrm{Fe}+\mathrm{Mg}) / 3$ (A) Mica branca nos metagranitos; (B) mica branca nos milonitos e filonitos. Símbolos conforme figura 4. 
Tabela 2 - Resultados das análises químicas (peso \%) por microssonda eletrônica de mica branca de metagranitos, milonitos e filonitos da ZCC. Valores de Ca, Ba, Mn e Cl estão abaixo do limite de detecção (nd). Simbolos: paragonita-estaurolita (prg-est), fengita-granada (feg-grn), alteração de granada (alt. grn) e de estaurolita (alt. est). (a) e (b) na numeração do grão referem-se a grãos zonados.

\begin{tabular}{|c|c|c|c|c|c|c|c|c|c|c|c|c|c|c|c|c|c|c|c|c|c|}
\hline \multirow[b]{3}{*}{ Grão } & \multicolumn{7}{|c|}{ Metagranito } & \multirow{2}{*}{\multicolumn{4}{|c|}{ milonito precoce }} & \multirow{2}{*}{\multicolumn{3}{|c|}{ prg-est filonito }} & \multirow{2}{*}{\multicolumn{3}{|c|}{ feg-grn filonito }} & \multicolumn{4}{|c|}{ fengita filonito } \\
\hline & \multicolumn{4}{|c|}{ M. branca I } & \multicolumn{3}{|c|}{ M. branca II } & & & & & & & & & & & \multicolumn{2}{|c|}{ alt. grn } & \multicolumn{2}{|c|}{ alt. est } \\
\hline & 1 & 2 & 5 & 8 & $11 \mathrm{a}$ & $11 \mathrm{~b}$ & 13 & $14 a$ & $14 \mathrm{~b}$ & $15 \mathrm{a}$ & $15 \mathrm{~b}$ & 22 & 23 & 24 & 18 & 19 & 20 & 21 & 22 & 23 & 24 \\
\hline $\mathrm{SiO}_{2}$ & 46,53 & 46,80 & 45,53 & 45,66 & 49,45 & 46,49 & 49,96 & 47,28 & 47,23 & 48,74 & 47,38 & 46,10 & 45,54 & 47,85 & 49,18 & 51,11 & 49,57 & 47,65 & 48,12 & 47,64 & 48,70 \\
\hline $\mathrm{TiO}_{2}$ & 0,92 & 1,05 & 1,32 & 1,52 & 0,21 & 0,94 & 0,01 & 0,71 & 0,56 & 0,20 & 0,43 & 0,40 & 0,36 & 0,47 & 0,03 & 0,05 & 0,06 & 0,32 & nd & 0,07 & 0,05 \\
\hline $\mathrm{Al}_{2} \mathrm{O}_{3}$ & 33,11 & 32,98 & 34,29 & 33,08 & 26,33 & 32,94 & 26,22 & 26,05 & 30,75 & 25,42 & 30,40 & 35,97 & 36,21 & 37,08 & 30,64 & 28,23 & 29,18 & 30,58 & 31,81 & 33,05 & 31,46 \\
\hline $\mathrm{FeO}$ & 2,53 & 2,19 & 2,03 & 2,04 & 4,84 & 2,50 & 4,30 & 7,21 & 4,65 & 7,58 & 4,87 & 0,78 & 0,66 & 0,75 & 1,75 & 2,77 & 2,99 & 2,62 & 1,76 & 1,32 & 1,87 \\
\hline $\mathrm{MgO}$ & 1,07 & 1,09 & 0,74 & 0,93 & 2,87 & 1,08 & 3,43 & 1,14 & 0,27 & 1,03 & 0,33 & 0,62 & 0,52 & 0,56 & 2,12 & 2,59 & 2,61 & 1,78 & 1,71 & 1,45 & 1,85 \\
\hline $\mathrm{Na}_{2} \mathrm{O}$ & 0,26 & 0,40 & 0,51 & 0,50 & 0,06 & 0,39 & 0,07 & 0,04 & 0,10 & 0,04 & 0,10 & 1,61 & 1,70 & 1,43 & 0,19 & 0,75 & 0,21 & 0,18 & 0,21 & 0,26 & 0,19 \\
\hline $\mathrm{K}_{2} \mathrm{O}$ & 10,94 & 10,97 & 10,63 & 10,83 & 10,87 & 10,92 & 11,29 & 11,07 & 10,94 & 10,96 & 10,91 & 9,00 & 8,59 & 8,27 & 10,99 & 10,14 & 10.64 & 10,85 & 10,62 & 10,84 & 10,84 \\
\hline $\mathrm{F}$ & nd & nd & nd & nd & nd & nd & nd & 0,09 & nd 0 & 0,09 & 0,50 & 0,22 & 0,57 & 0,31 & nd & nd & nd & nd & nd & nd & nd \\
\hline Total & 95,48 & 95,58 & 95,22 & 94,66 & 94,94 & 95,46 & 95,61 & 94,40 & 94,93 & 95,01 & 94,93 & 94,74 & 93,82 & 96,58 & 95,20 & 95,93 & 95,65 & 94,11 & 94,40 & 95,03 & 95,28 \\
\hline \multicolumn{22}{|c|}{ Fórmula estrutural com base em 22 oxigènios } \\
\hline Si & 6,24 & 6,26 & 6,11 & 6,18 & 6,75 & 6,24 & 6,77 & 6,64 & 6,45 & 6,79 & 6,48 & 6,13 & 6,10 & 6,19 & 6,57 & 6,78 & 6,63 & 6,48 & 6,47 & 6,37 & 6,50 \\
\hline $\mathrm{Al}^{\mathrm{iv}}$ & 1,76 & 1,74 & 1,89 & 1,82 & 1,25 & 1,76 & 1,23 & 1,36 & 1,55 & 1,21 & 1,52 & 1,87 & 1,90 & 1,81 & 1,43 & 1,22 & 1,37 & 1,52 & 1,53 & 1,63 & 1,50 \\
\hline $\mathrm{Ti}$ & 0,09 & 0,11 & 0,13 & 0,15 & nd & 0,09 & nd & 0,07 & 0,06 & 0,02 & 0,04 & 0,04 & 0,04 & 0,05 & nd & nd & nd & 0,03 & nd & nd & nd \\
\hline $\mathrm{Al}^{\mathrm{vi}}$ & 3,48 & 3,47 & 3,54 & 3,45 & 2,99 & 3,46 & 2,96 & 2,95 & 3,40 & 2,97 & 3,38 & 3,77 & 3,82 & 3,84 & 3,40 & 3,20 & 3,23 & 3,38 & 3,52 & 3,58 & 3,46 \\
\hline Fé & 0,28 & 0,25 & 0,23 & 0,23 & 0,55 & 0,28 & 0,49 & 0,85 & 0,53 & 0,88 & 0,56 & 0,09 & 0,07 & 0,08 & 0,20 & 0,31 & 0,33 & 0,3 & 0,20 & 0,15 & 0,21 \\
\hline $\mathrm{Mg}$ & 0,21 & 0,22 & 0,15 & 0,19 & 0,58 & 0,22 & 0,69 & 0,24 & 0,05 & 0,21 & 0,07 & 0,12 & 0,10 & 0,11 & 0,42 & 0,51 & 0,52 & 0,36 & 0,34 & 0,29 & 0,37 \\
\hline $\mathrm{Na}$ & 0,07 & 0,10 & 0,13 & 0,13 & 0,02 & 0,10 & 0,02 & 0,01 & 0,03 & 0,01 & 0,03 & 0,42 & 0,44 & 0,36 & 0,05 & 0,19 & 0,05 & 0,05 & 0,05 & 0,07 & 0,05 \\
\hline $\mathrm{K}$ & 1,87 & 1,87 & 1,82 & 1,87 & 1,89 & 1,87 & 1,95 & 1,98 & 1,91 & 1,95 & 1,90 & 1,53 & 1,47 & 1,36 & 1,87 & 1,72 & 1,82 & 1,88 & 1,82 & 1,85 & 1,85 \\
\hline$F$ & nd & nd & nd & nd & nd & nd & nd & 0,04 & nd & 0,04 & 0,22 & 0,09 & 0,25 & 0,13 & nd & nd & nd & nd & nd & nd & nd \\
\hline $\mathrm{T}$ (cat) & 14,02 & 14,02 & 14,02 & 14,03 & 14,06 & 14,04 & 14,12 & 14,13 & 13,99 & 14,08 & 13,99 & 13,98 & 13,96 & 13,80 & 13,97 & 13,96 & 13,99 & 14,00 & 13,95 & 13,97 & 13,96 \\
\hline
\end{tabular}

sição mais ferri-fengítica (Fig. 4).

Nos filonitos, são individualizadas duas variedades de mica branca, paragonita e muscovita-fengita. A paragonita ocorre na matriz e como produto de alteração da albita nos paragonitaestaurolita filonitos. Além do $\mathrm{Na}$, caracteriza-se pelos valores mais elevados e $\mathrm{Al}$ (tabela 2).

A muscovita-fengita ocorre na matriz dos fengita-granada filonitos. Nos fengita filonitos ocorre tanto na matriz quanto como produto de alteração de granada e estaurolita (Fig. 3b e 10). Os termos mais fengíticos, com valores de $\mathrm{Mg}$ de até $0,5 \%$, ocorrem na matriz. Os produtos de alteração de granada e estaurolita apresentam termos intermediários entre muscovita e fengita.

É possível observar dois trends químicos principais para a mica branca, exceto a paragonita (Fig. 4). O primeiro corresponde à mica I e II nos granitos e milonitos, com lamelas variando entre os termos muscovita e ferri-fengita e valores mais elevados de $\mathrm{Al}{ }^{\text {iv }}$. O segundo trend corresponde à mica nos filonitos, com termos variando entre muscovita e fengita, com tendência à composição fengítica e valores mais elevados de Mg. Verifica-se que a mica branca apresenta grande heterogeneidade composicional nas rochas estudadas.

Clorita Diferentes gerações de clorita com composições químicas variadas são observadas nas rochas estudadas ao longo da evolução da ZCC. Foram realizadas 29 análises de clorita em 27 grãos de seis amostras representativas.

Nos metagranitos, a clorita deve ser produto de transfor- mação pseudomórfica de biotita, com associação clorita, mica branca, rutilo e zircão, pois apresenta características ópticas de biotita como pleocrósmo entre marrom e bege. No entanto, todas as análises apontam para uma mistura finamente intercalada de clorita-mica branca II e pode ser classificada como chamosita magnesiana (cf. Bayliss, 1975) ou brunsvigita (cf. Foster 1962, Fig. 6). Algumas lamelas apresentam-se zonadas quimicamente com porções mais ricas em $\mathrm{Fe}$ e outras mais ricas em $\mathrm{Mg}$ (Fig. 7A). As lamelas não zonadas podem apresentar variações entre os dois tipos de composição.

O caráter metamórfico da clorita, tanto no protólito granítico como nos filonitos, pode ser visualizado no diagrama de Velde (1985, Fig. 8). Também se observa, neste mesmo diagrama, o caráter mais magnesiano da clorita que ocorre na matriz do fengita filonito.

Nos filonitos, a clorita ocorre em diferentes sítios estruturais, marcando várias gerações: porfiroblastos (clorita I); na matriz (clorita II); como produto de alteração de granada e estaurolita; $\mathrm{e}$ em vênulas monominerálicas. Os porfiroblastos de clorita fazem parte da paragênese clorita, estaurolita e/ou granada, paragonita e turmalina. (tabela1). Os porfiroblastos tipo peixe, (mica fish), têm deformação intracristalina e os limites das lamelas são irregulares (Fig. 7B). Os grãos são marrom avermelhados (em luz natural) e levemente pleocróicos, cor característica da biotita, contudo as análises apontam, novamente, para uma mistura de muscovita-clorita e muscovita. Na matriz e como produto de alteração de granada e estaurolita, as lamelas são incolores e mui- 
to pequenas (Fig. 3B). As vênulas de clorita são discordantes da foliação $S_{n+2}$. Esta clorita é verde clara, pleocróica, classificada como chamosita magnesiana a chamosita alumino-magnesiana (cf. Bayliss, 1975) ou brunsvigita a ripidolita (Fig. 6).

A principal característica da clorita, tanto nos metagranitos como nos filonitos, é a heterogeneidade composicional (tabela 3). A clorita dos metagranitos apresenta os valores mais altos de $\mathrm{Si}$ e os valores mais baixos de $\mathrm{Al}{ }^{\text {iv }}$. A razão $\mathrm{Fe} / \mathrm{Mg}$ é alta, entre 1,33 e 2,48, provavelmente pela substituição incompleta da biotita por clorita. No fengita-granada filonito, a clorita tem alto $\mathrm{Si}$, baixo $\mathrm{Al}_{(\mathrm{T})}$ e Fe/Mg entre 1,25 e 1,52. No paragonita-estaurolita filonito, os porfiroblastos de clorita tem os valores mais altos de Fe e também alto $\mathrm{Al}^{\mathrm{i}}$, com $\mathrm{Fe} / \mathrm{Mg}$ alta, entre 1,29 e 1,8 (provavelmente pela substituição incompleta da biotita por clorita). A clorita proveniente de alteração da granada tem valores altos de $\mathrm{Al}^{\text {vi }}$, baixo $\mathrm{Si}$ e Fe/Mg entre 1,5 e 1,52. A clorita proveniente de alteração da estaurolita tem valores bem heterogêneos, com $\mathrm{Al}^{\text {iv }}$ entre 2,31 e 4,04, Al entre 2,61 e 4,41, Si 3,96 a 5,69 e Fe/Mg 1,03 a 3.63. No fengita filonito, a clorita da matriz tem os valores mais altos de $\mathrm{Mg}$, alto $\mathrm{Si}$ e a razão $\mathrm{Fe} / \mathrm{Mg}$ mais baixa, entre 0,67 a 1,25 . As vênulas monominerálicas de clorita têm valores altos de $\mathrm{Fe}$ e $\mathrm{Al}_{(\mathrm{T})}$ e Fe/Mg entre 1,55 a 1,63.

No diagrama $\mathrm{Al}^{\text {iv }} / \mathrm{Fe} /(\mathrm{Fe}+\mathrm{Mg})$, mostrado na figura 9, podese notar que $A l^{\text {iv }}$ tem uma correlação positiva com $\mathrm{Fe} /(\mathrm{Fe}+\mathrm{Mg})$, como já observado por Foster (1962) e Zhang \& Fyfe (1995), dentre outros. Observa-se uma correlação direta entre $\mathrm{Al}^{\mathrm{iv}}$ e Fe, por um lado, e $\mathrm{Si}^{4+}$ e $\mathrm{Mg}$ por outro, como já descrito por Cathelineau \& Nieva (1985), em que a substituição do $\mathrm{Si}^{4+}$ pelo $\mathrm{Al}^{\mathrm{iv}} \mathrm{e}$ associada a mudanças no tamanho de cátions ou ajuste estrutural na clorita. Isto permite o íon $\mathrm{Fe}^{2+}$ substituir o $\mathrm{Mg}$ na estrutura do mineral. Três trends positivos podem ser individualizados na figura $9:\left(1^{\circ}\right)$ reúne a clorita mais férrica dos metagranitos e paragonita-estaurolita filonitos; $\left(2^{\circ}\right)$ clorita do fengita-granada filonitos, alteração de granada e vênulas posteriores; $\left(3^{\circ}\right)$ da clorita mais magnesiana nos fengita filonitos e alteração de estaurolita. Próximo da zona mineralizada, a relação entre as rochas menos deformadas (metagranitos) e as mais filonitizadas (fengita filonitos), mostra um acréscimo relativo no conteúdo de magnésio e uma diminuição no conteúdo de ferro (Fig. 9). As vênulas posteriores, contudo, tem valores altos de ferro.

Granada e Estaurolita Em granada, foram realizadas oito análises em grãos diferentes de duas amostras e em estaurolita apenas duas análises em um grão, sem um bom fechamento químico, devido ao alto grau de transformação em clorita e muscovita.

A granada forma níveis de porfiroblastos orientados segundo a foliação $S_{n+2}$ no fengita-granada filonito, ou está inclusa em estaurolita. Os grãos estão parcialmente transformados em muscovita fengítica, clorita e calcita e apresentam sombra de pressão assimétrica preenchida pelos mesmos minerais. Trata-se de almandina (Deer et al. 2002), que apresenta a seguinte composição: 73,5 a 79 mol \% de almandina (média 75,9 mol \%); 10,5 a 14 mol \% de piropo (média $12,5 \mathrm{~mol} \%$ ); 5 a $11 \mathrm{~mol} \%$ de espessartita (média $6,5 \mathrm{~mol} \%$ ); 2,4 a $8 \mathrm{~mol} \%$ de grossulária (média 5,0 mol \%).

A estaurolita ocorre como porfiroblastos prismáticos de $5 \mathrm{~cm}$ de comprimento no paragonita-estaurolita filonito (Fig. 10). Os grãos orientados segundo a foliação $\mathrm{S}_{\mathrm{n}+2}$ são mais deformados tipo augen, enquanto os grãos que fazem ângulo com a foliação são menos deformados, mais euédricos. Sombras de pressão são comuns, preenchidas por clorita, muscovita, calcopirita e esfalerita. Vênulas monominerálicas de pirita podem delimitar os limites dos grãos (Fig. 10). A estaurolita apresenta inclusões de granada e turmalina e trilhas de rutilo, titanita, apatita e monazita. A turmalina inclusa mantém a orientação preferencial à foliação $_{\mathrm{Sn}+2}$, da matriz. Os porfiroblastos estão parcial ou totalmente

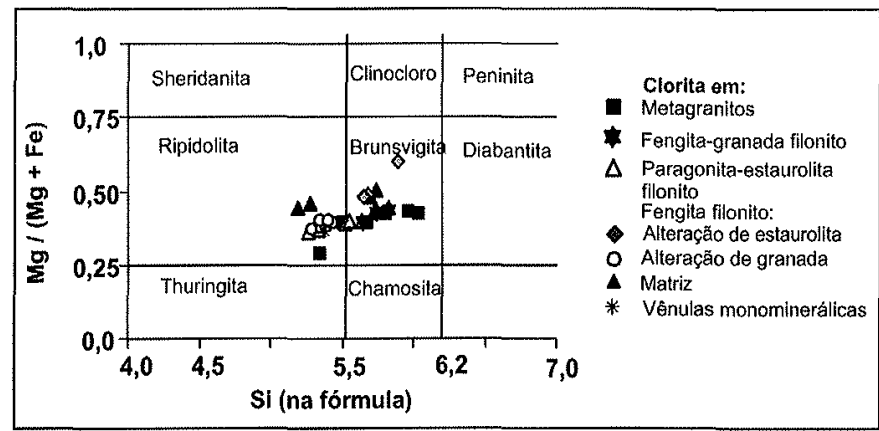

Figura 6 - Classificação da clorita na Zona de Cisalhamento Cachimbo, conforme diagrama $\mathrm{Si}-\mathrm{Mg} /(\mathrm{Mg}+\mathrm{Fe})$ de Foster (1962).

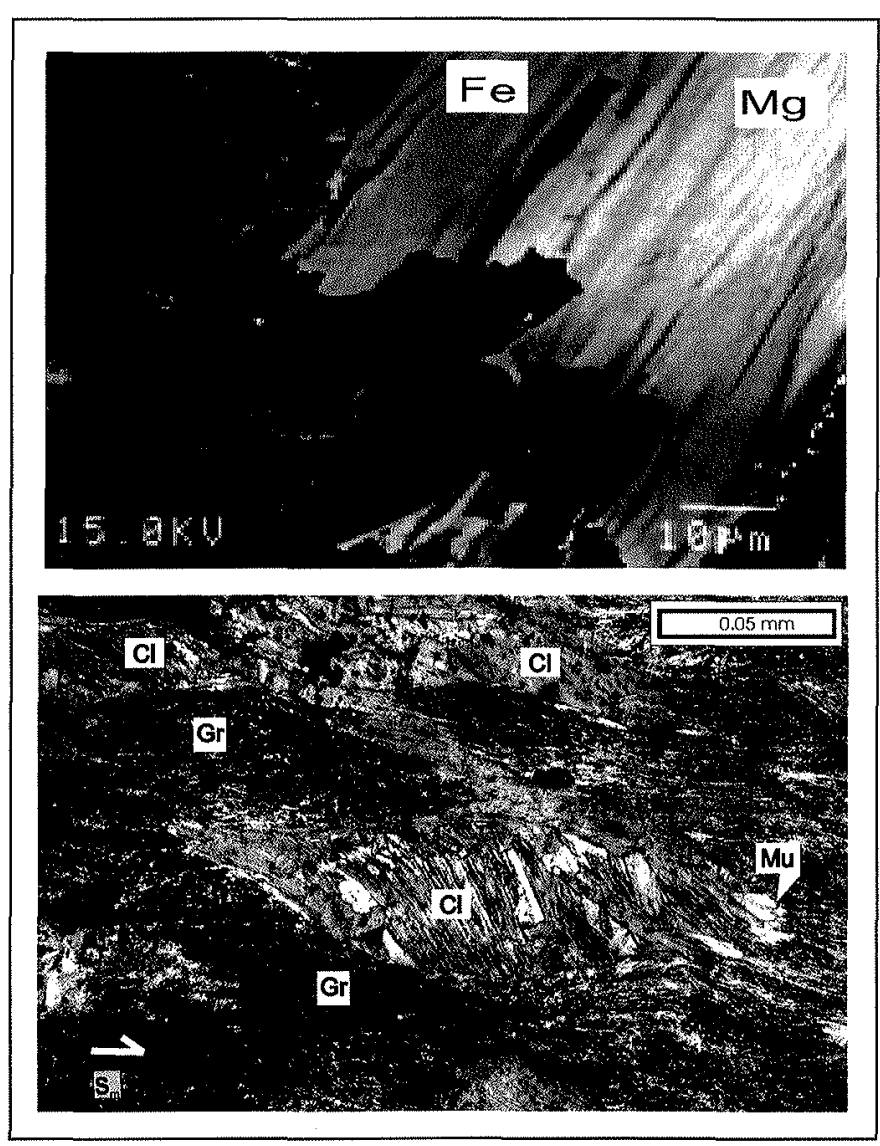

Figura 7 - (A) Imagem de elétrons retroespalhados de lamela de clorita com zonação composicional $\mathrm{Fe}$ - Mg nos metagranitos da Zona de Cisalhamento Cachimbo. (B) Porfiroblastos tipo mica fish de clorita (Cl) assimétrico, marcando a superficie $S$ da foliação milonítica $S_{n+2}$ no paragonita-estaurolita filonito. Os planos de clivagem são dilatados com formação de muscovita (Mu) $e$ clorita II (Cl II). A sombra de pressão é composta por Mu e Cl II, que marcam igualmente a superficie $C$ da foliação milonítica $S_{n+2}$ - Grafita (Gr) ocorre substituindo muscovita e clorita.

transformados em muscovita-fengita e clorita. Segundo Deer et al. (2002), a estaurolita é do tipo férrica com a razão $\mathrm{Fe} /(\mathrm{Fe}+\mathrm{Mg})$ entre 0,15 e 0,19 e valores de Ti em torno de $0,1 \%$.

Turmalina Em turmalina, foram realizadas 26 análises em 15 grãos de quatro amostras diferentes. A turmalina ocorre em todos os filonitos, na matriz ou como inclusão em estaurolita. Os 


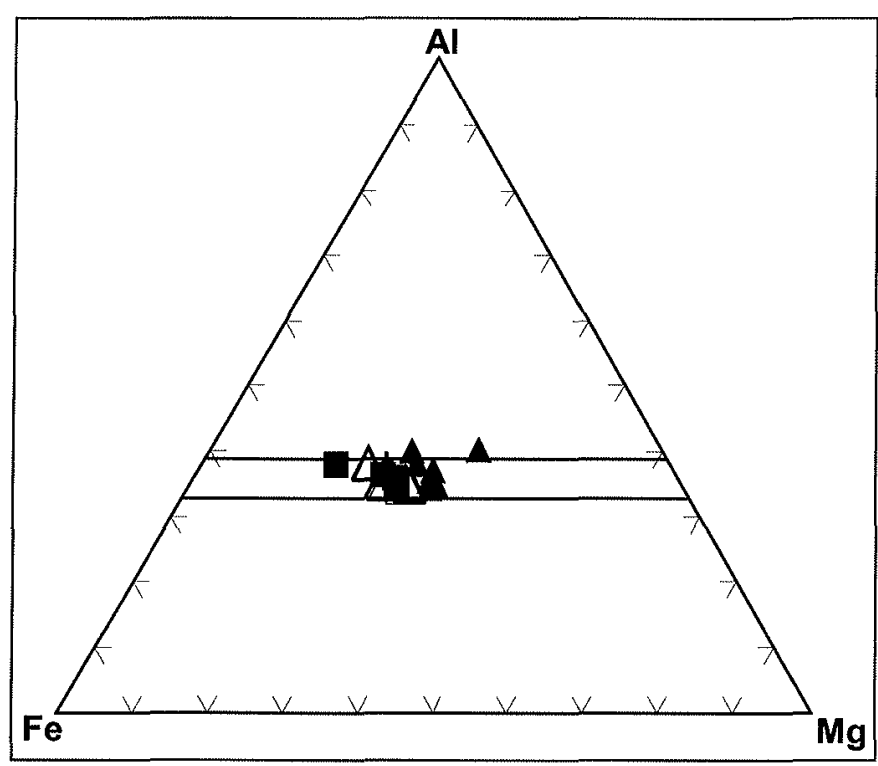

Figura 8-Diagrama Al-Fe-Mg conforme Velde (1985). Ocampo entre as linhas caracteriza clorita metamórfica, evidenciando este caráter para todas as amostras analisadas tanto metagranito como rochas de cisalhamento. Simbolos conforme figura 6.

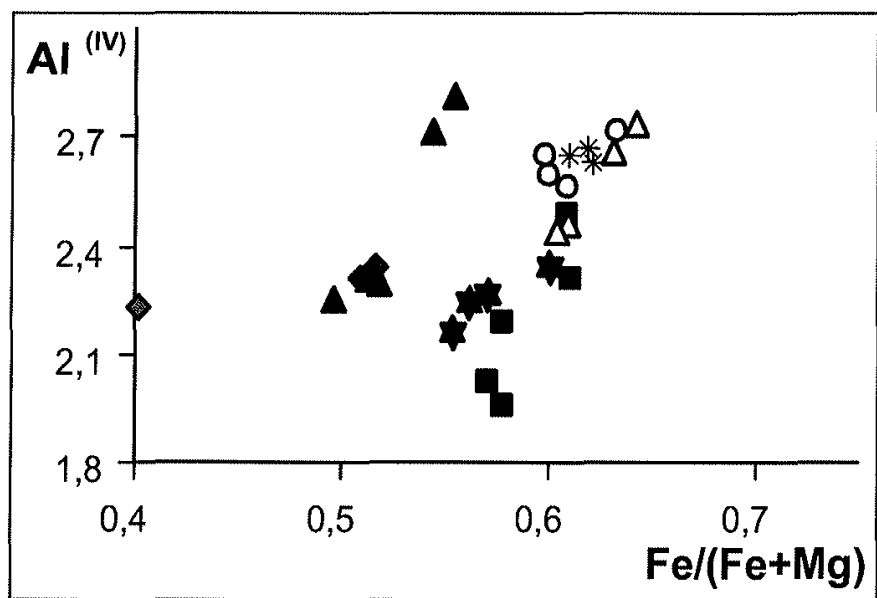

Figura 9 - Diagrama da variação de Aliv em relação às razões de $\mathrm{Fe} /(\mathrm{Fe}+\mathrm{Mg})$ na clorita da Zona de Cisalhamento Cachimbo. Simbolos conforme figura 6.

grãos são orientados segundo a foliação, mesmo como inclusões e muitos apresentam sombra de pressão preenchida por muscovita e clorita (Fig. 11).

Quimicamente, a turmalina pertence à série de solução sólida Schorlita-Dravita $\left(\mathrm{NaFe}_{3} \mathrm{Al}_{6}\left(\mathrm{BO}_{3}\right)_{3} \mathrm{Si}_{6} \mathrm{O}_{18}(\mathrm{OH})_{4}-\mathrm{NaMg}\right.$ $\left.\mathrm{Al}_{6}\left(\mathrm{BO}_{3}\right)_{3} \mathrm{Si}_{6} \mathrm{O}_{18}(\mathrm{OH})_{4}\right)$, conforme a classificação de Deer et al. (2002) e Henry \& Guidotti (1985, Fig. 12). Como as amostras situam-se acima da linha Schorlita-Dravita, pode-se inferir que a turmalina não apresenta quantidades apreciáveis de $\mathrm{Fe}^{3+}$, conforme discutido por Henry \& Guidotti (op. cit.).

Os grãos de turmalina apresentam-se zonados ou não, com dois padrões de zonação. A zonação tipo 1 tem núcleo verde claro e borda marrom escuro em luz natural. Os limites entre núcleo e borda são bem definidos. Quimicamente, o núcleo é enriquecido em $\mathrm{Si}$ e $\mathrm{Fe}$ e a borda enriquecida em $\mathrm{Mg}$, Ca e Ti (tabela 4). A substituição principal, que parece ter ocorrido do

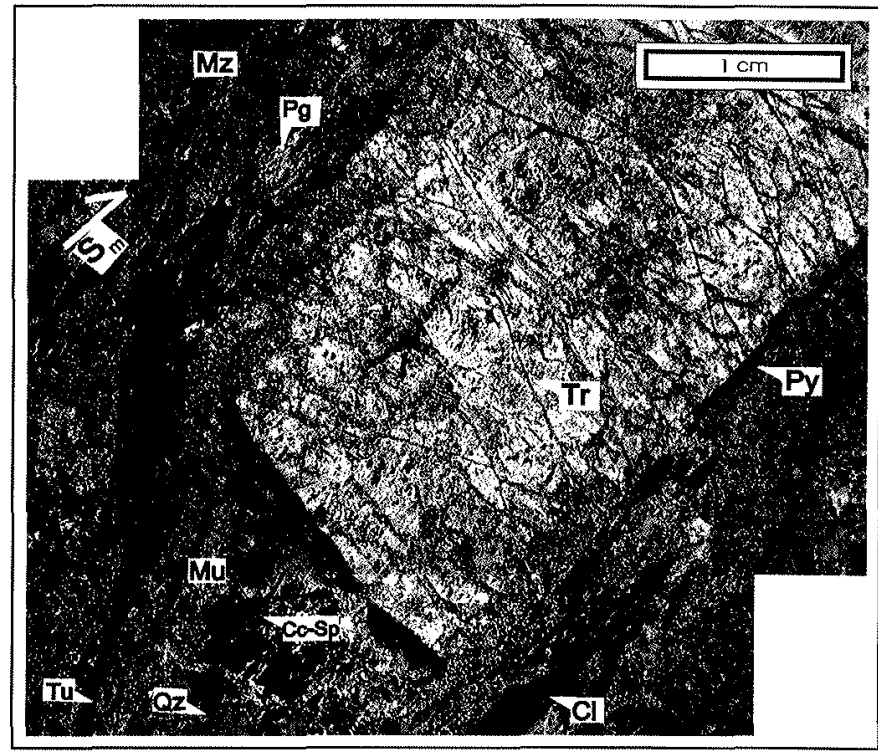

Figura 10-Fotomicrografia em $L P$ de parte de um porfiroblasto de estaurolita concordante com a foliação $\left(S_{n+2}\right)$ marcada por clorita (Cl), paragonita (Pg), turmalina (Tu) e quartzo ( $Q z)$. Sombra de pressão preenchida por clorita, muscovita, calcopirita $(C c)$ e esfalerita (Sp).Vênulas de pirita (Py) marcam o limite inferior do porfiroblasto.

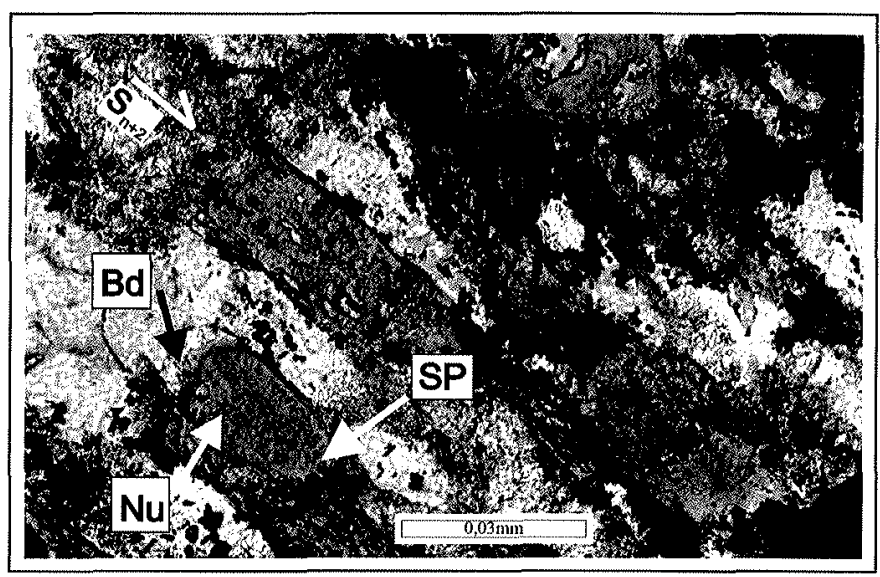

Figura 11 - Fotomicrografia em luz natural ( $L N)$ de grãos de turmalina (Tu) orientados segundo a foliação milonítica $\left(S_{n+2}\right)$. Detalhe da zonação química tipo 2, com núcleo mais escuro (Nu) e borda mais clara (Bd). Sombra de pressão (Sp) indicada.

centro para a borda da turmalina tipo 1 , foi $\mathrm{Fe}^{2+} \mathrm{y}=\mathrm{Mgy}$, em que y é um sítio octaédrico (cf. Henry \& Guidotti 1985).

A zonação tipo 2, mais comum, tem núcleo verde azulado escuro e borda marrom claro (Fig. 11). O núcleo é enriquecido em Si, Fe, Ti e Na, a borda enriquecida em $\mathrm{Al}$ e Mg. A substituição possivelmente ocorrida do centro para a borda do tipo 2 foi $\mathrm{Na}_{x}+\mathrm{Fe}^{2+} \mathrm{y}=\mathrm{Mg}_{\mathrm{x}}+\mathrm{Al} y$, em que $\mathrm{x}$ representa o sítio dos álcalis e y é um sítio octaédrico. Independente do tipo de zonação, a maior variação nos grãos de turmalina é na razão $\mathrm{Fe} / \mathrm{Mg}$, no núcleo entre 0,7 e 1,4 e na borda 0,47 a 0,55.

Conforme figura 12, o núcleo da turmalina tipo $1 \mathrm{tem}$ um enriquecimento de $\mathrm{Fe}$ e $\mathrm{Al}$ e o núcleo da turmalina tipo 2 é relativamente empobrecido em Al. A diferença composicional entre os grãos de turmalina tipo 1 e 2 sugere que eles se originaram em condições ambientais diferentes. Contudo, há uma simila- 
Tabela 3- Resultados das análises químicas (peso \%) por microssonda eletrônica de clorita de granitos, milonitos e filonitos da ZZC. Valores de $\mathrm{Ca}, \mathrm{Ba}, \mathrm{Mn}, \mathrm{Cr}$ e Cl estão abaixo do limite de deteç̧ão (nd). Símbolos: paragonita-estaurolita (prg-est), fengita-granada (feg-grn), matriz (Mtz), alteração de granada (alt. grn) e de estaurolita (alt. est). (a) e (b) na numeração do grão referem-se a grãos zonados. T1 e T2 referem-se aos resultados de temperatura pelo geotermômetro da clorita conforme Cathelineau (1988) e Jowett (1991), respectivamente.

\begin{tabular}{|c|c|c|c|c|c|c|c|c|c|c|c|c|c|c|c|c|c|c|c|}
\hline \multirow[b]{3}{*}{ grãos } & \multirow{2}{*}{\multicolumn{4}{|c|}{ metagranitos }} & \multicolumn{5}{|c|}{ Feg-grn filonito } & \multirow{2}{*}{\multicolumn{3}{|c|}{ Prg-est filonito }} & \multicolumn{7}{|c|}{ Fengita filonito } \\
\hline & & & & & \multicolumn{3}{|c|}{ matriz } & \multicolumn{2}{|c|}{ porfiroblast } & & & & \multirow{2}{*}{$\frac{\text { Mtz }}{23}$} & \multicolumn{2}{|c|}{ alt. grn } & \multicolumn{2}{|c|}{ alt. est } & \multicolumn{2}{|c|}{ vênulas } \\
\hline & $2 a$ & $2 b$ & 3 & 6 & 7 & $9 \mathbf{a}$ & $9 b$ & 18 & 19 & 12 & $14 \mathfrak{a}$ & $14 b$ & & 25 & 17 & 10 & $12 \mathrm{a}$ & 21 & 22 \\
\hline $\mathrm{SiO}_{2}$ & 27,62 & 25,20 & 26,17 & 24,33 & 27,24 & 24,68 & 24,38 & 26,65 & 26,72 & 25,47 & 23,90 & 25,98 & 25,43 & 24,80 & 24,09 & 26,93 & 26,75 & 24,41 & 24,47 \\
\hline $\mathrm{TiO}_{2}$ & 0,53 & 0,05 & 1,19 & 0,20 & 0,58 & 0,04 & 0,06 & 0,72 & 0,25 & 0,21 & 0,12 & 0,24 & 0,05 & 0,09 & 0,07 & 0,52 & 0,51 & 0,10 & nd \\
\hline $\mathrm{Al}_{2} \mathbf{O}_{3}$ & 18,75 & 20,26 & 19,50 & 21,18 & 19,18 & 21,95 & 23,16 & 18,84 & 18,62 & 19,81 & 21,32 & 19,28 & 19,56 & 20,70 & 21,07 & 20,31 & 19,85 & 20,99 & 21,63 \\
\hline $\mathrm{FeO}$ & 27,02 & 30,12 & 28,93 & 34,50 & 25,43 & 27,48 & 27,41 & 28,59 & 28,78 & 30,75 & 31,53 & 30,05 & 30,54 & 29,88 & 31,48 & 25,01 & 26,07 & 30,61 & 30,37 \\
\hline Mno & 0,19 & 0,19 & 0,18 & 0,38 & 0,23 & 0,37 & 0,40 & 0,32 & 0,38 & 0,24 & 0,21 & 0,29 & 0,21 & 0,25 & 0,22 & 0,33 & 0,32 & 0,28 & 0,32 \\
\hline MgO & 11,40 & 10,80 & 10,34 & 7,81 & 14,42 & 12,90 & 12,33 & 12,04 & 12,54 & 11,03 & 9,84 & 11,24 & 11,26 & 11,19 & 10,21 & 13,54 & 13,69 & 10,53 & 10,48 \\
\hline $\mathrm{CaO}$ & 0,15 & nd & 0,17 & nd & 0,16 & nd & 0,05 & 0,14 & 0,04 & nd & nd & nd & nd & 0,06 & 0,11 & 0,10 & 0,17 & nd & nd \\
\hline $\mathrm{Na}_{2} \mathrm{O}$ & nd & nd & 0,08 & nd & nd & nd & nd & nd & 0,04 & nd & 0,09 & nd & nd & 0,11 & 0,07 & 0,05 & 0,04 & 0,07 & nd \\
\hline $\mathrm{K}_{2} \mathrm{O}$ & 0,29 & 0,09 & 0,13 & nd & 0,33 & nd & nd & 0,22 & 0,17 & 0,28 & nd & 0,37 & nd & nd & $\mathrm{Nd}$ & 0,52 & 0,33 & nd & nd \\
\hline$F$ & 0,30 & 0,30 & 0,24 & 0,32 & 0,17 & 0,13 & 0,15 & 0,14 & 0,19 & 0,13 & 0,13 & 0,13 & 0,17 & 0,13 & 0,11 & 0,13 & 0,14 & 0,12 & 0,08 \\
\hline Total & 86,27 & 87,08 & 86,93 & $\mathbf{8 8 , 7 8}$ & 87,81 & 87,64 & 88,04 & 87,74 & 87,81 & 87,95 & 87,22 & $\mathbf{8 7 , 6 4}$ & 87,33 & 87,25 & 87,47 & 87,50 & 87,91 & 87,15 & 87,38 \\
\hline \multicolumn{20}{|c|}{ Fórmula estrutural com base $\mathrm{cm} 28$ oxigênios } \\
\hline $\mathbf{S i}$ & 5,98 & 5,52 & 5,69 & 5,35 & 5,75 & 5.28 & 5,19 & 5,73 & 5,75 & 5,53 & 5,27 & 5,65 & 5,56 & 5,41 & 5,29 & 5,69 & 5,66 & 5,35 & 5,33 \\
\hline $\mathbf{A l}^{\mathrm{N}}$ & 2,02 & 2,48 & 2,31 & 2,65 & 2,25 & 2,72 & 2,81 & 2,27 & 2,25 & 2,47 & 2,73 & 2,35 & 2,44 & 2,59 & 2,71 & 2,31 & 2,34 & 2,65 & 2,67 \\
\hline $\mathbf{T i}$ & 0,09 & nd & 0,19 & nd & 0,09 & nd & nd & 0,12 & 0,04 & nd & nd & 0,04 & nd & nd & nd & 0,08 & 0,08 & nd & nd \\
\hline $\mathbf{A}^{\mathbf{v}}$ & 2,77 & 2,75 & 2,69 & 2,85 & 2,52 & 2,82 & 3,00 & 2,51 & 2,48 & 2,61 & 2,81 & 2,59 & 2,60 & 2,73 & 2,75 & 2,75 & 2,61 & 2,78 & 2,89 \\
\hline $\mathrm{Fe}$ & 4,89 & 5,52 & 5,26 & 6,35 & 4,49 & 4,92 & 4,88 & 5,14 & 5,18 & 5,59 & 5,81 & 5,46 & 5,58 & 5,45 & 5,78 & 4,42 & 4,61 & 5,61 & 5,53 \\
\hline $\mathbf{M n}$ & nd & 0,04 & nd & 0,07 & 0,04 & 0,07 & 0,07 & 0,06 & 0,07 & 0,04 & 0,04 & 0,05 & 0,04 & 0,05 & 0,04 & 0,06 & 0,06 & 0,05 & 0,06 \\
\hline $\mathbf{M g}$ & 3,68 & 3,52 & 3,35 & 2,56 & 4,54 & 4,11 & 3,91 & 3,86 & 4,02 & 3,57 & 3,23 & 3,64 & 3,67 & 3,64 & 3,34 & 4,26 & 4,32 & 3,44 & 3,40 \\
\hline $\mathrm{Ca}$ & nd & nd & 0,04 & nd & 0.04 & nd & nd & nd & nd & nd & nd & nd & nd & nd & 0,03 & nd & 0,04 & nd & nd \\
\hline $\mathrm{Na}$ & nd & nd & nd & nd & nd & nd & nd & nd & nd & nd & 0,04 & nd & nd & 0,05 & 0,03 & nd & nd & nd & nd \\
\hline $\mathbf{K}$ & 0,08 & nd & 0,04 & nd & 0,09 & nd & nd & 0,06 & 0,05 & 0,08 & nd & 0,10 & nd & nd & nd & 0,14 & 0,09 & nd & nd \\
\hline $\mathbf{F}$ & 0,21 & 0,21 & 0,17 & 0,22 & 0,11 & 0,09 & 0,10 & 0,10 & 0,13 & 0,09 & 0,09 & 0,09 & 0,12 & 0,09 & 0,08 & 0,09 & 0,09 & 0,08 & 0,06 \\
\hline$T$ (cat) & 19,58 & 19,88 & 19,65 & 19,87 & 19,82 & 19,94 & 19,89 & 19,80 & 19,87 & 19,93 & 19,96 & 19,89 & 19,92 & 19,94 & 19,88 & 19,77 & 19,83 & 19,93 & 19,90 \\
\hline $\mathbf{T}_{1}\left({ }^{\circ} \mathbf{C}\right)$ & 271,4 & 346,0 & 318,9 & 376,4 & 305,7 & 382,2 & 396,9 & 311,3 & 307,8 & 344,4 & 386,9 & 325,0 & 339,4 & 363,2 & 383,5 & 315,7 & 320,7 & 373,4 & 376,6 \\
\hline $\mathbf{T}_{2}\left({ }^{\circ} \mathrm{C}\right)$ & 281,7 & 357,0 & 329,6 & 387,7 & 316,3 & 393,5 & 408,3 & 321,9 & 318,4 & 355,4 & 398,3 & 335,7 & 350,3 & 374,3 & 395,0 & 326,4 & 331,4 & 384,7 & 387,9 \\
\hline
\end{tabular}

ridade química nas bordas tanto da turmalina tipo 1 como da tipo 2, sugerindo que as bordas dos dois tipos podem ter sido formadas sob condições físico-químicas análogas.

Carbonato Em carbonato, foram realizadas 17 análises em três amostras. O carbonato está ausente nos metagranitos e milonitos. Ocorre na ordem de $3 \%$ nos filonitos, nos seguintes sítios estruturais: (a) agregados de carbonato e paragonita, com grãos bem formados, marcando a foliação $S_{n+2}$ no paragonita-estaurolita filonito. Pode ocorrer grafita em limite de grão de carbonato; (b) carbonato, muscovita e clorita como produto de alteração da granada no fengita filonito e, (c) vênulas de carbonato, de diversas gerações, concordantes ou discordantes da foliação $\mathrm{S}_{n+2}$. As vênulas discordantes têm estrutura tipo crack-seal com duas gerações de carbonato. Quartzo, pirita e calcopirita podem estar associados às vênulas.

$O$ carbonato é do tipo calcita e apresenta valores de $\mathrm{CaCO}_{3}$ entre 95 e $99 \%$, de $\mathrm{MnCO}_{3}$ entre 0,07 a 2,11\%; de $\mathrm{FeCO}_{3}$ entre 0,06 e $0,44 \%$; e de $\mathrm{Mg} \mathrm{CO}_{3}$ entre 0,03 a $0,45 \%$. As principais substituições ocorrem entre $\mathrm{CaCO}_{3}$ e $\mathrm{MnCO}_{3}$. O carbonato que ocorre com sulfetos nas vênulas apresenta-se quimicamente muito variado.

Grafita A zona potencialmente mineralizada é marcada pelo aparecimento de níveis centimétricos de grafita e pirita nos fi- lonitos. O grafita ocorre disseminado, substituindo carbonato ou filossilicatos (Fig. 10). O produto final é uma rocha a base de grafita e quartzo, o grafita filonito, encaixante dos veios de quartzo mineralizados. Nos veios, o grafita é um mineral secundário. Ocorre disseminado com quartzo ou, em níveis de cisalhamento, entre fitas de quartzo.

Análises de microespectroscopia Raman foram realizadas em amostras dos filonitos e veios de quartzo mineralizados, com o intuito de determinar o grau de cristalinidade do grafita. O grau da ordem e grau de cristalinidade progressiva do grafita é proporcional ao aumento das condições metamórficas, os quais provocam variações no diâmetro do plano basal principal deste mineral (Pasteris \& Wopenka,1991; Wopenka \& Pasteris, 1993).

As amostras de grafita da ZCC foram analisadas na região de primeira ordem do espectro. $O$ espectro mostra a banda $G$, ou banda do grafita, a $1584 \mathrm{~cm}^{-1}$ e a banda $D_{1}$ a $1355 \mathrm{~cm}^{-1}$, com o pico muito pouco desenvolvido. $A$ banda $D_{2}$, a $1620 \mathrm{~cm}^{-1}$, não é observada. A razão $R^{2}\left(D_{1} /\left(G+D_{1}+D_{2}\right)\right.$ é 0,46 (cf. Beyssac et al. 2002).

Segundo Beyssac et al.(op. cit), a banda $\mathrm{D}_{2}$ ocorre somente em grafita com carbono pobremente ordenado, não sendo o caso do grafita estudado. O espectro estudado é compatível com o espectro de grafita de metamorfismo de fácies anfibolito, zona da estaurolita, (Pasteris \& Wopenka, op.cit.), e o valor de $\mathrm{R}^{2}$ compatível com temperaturas de $500^{\circ}$ a $550^{\circ} \mathrm{C}$ (cf. Beyssac et al. 2002). 
Sulfetos e ouro Em pirita foram realizadas 14 análises em cinco amostras e em calcopirita, seis análises em três amostras. A pirita é o sulfeto dominante nos filonitos e veios de quartzo mineralizados. A calcopirita ocorre em equilíbrio com a pirita, ou como produto de alteração desta. Traços de arsenopirita, esfalerita e galena ocorrem bordejando os grãos de calcopirita. Duas gerações de pirita são observadas: pirita I e pirita II. A pirita I ocorre como grãos isolados ou associada à calcopirita em:

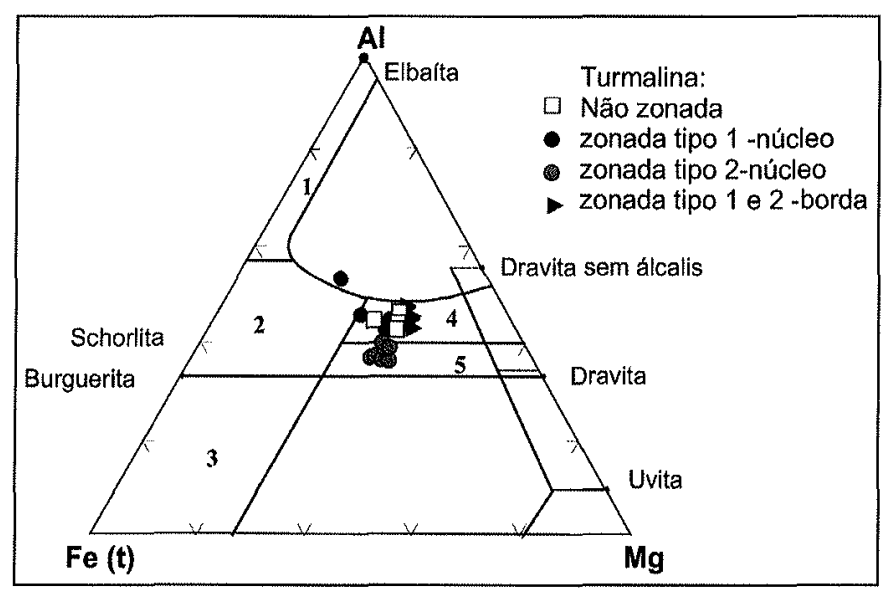

Figura 12 - Diagrama Al-Fe $-M g$ (proporção molecular) para turmalina, conforme Henry \& Guidotti (1985). Alguns membros finais são colocados como referência. Campos conforme os autores: ( 1 e 2) granitos; (3) granitos oxidados; (4) metapelitos contendo fase saturada em Al; (5) metapelitos não contendo fase saturada em Al. (a) vênulas de carbonato; (b) sombra de pressão de estaurolita e granada (Fig. 10) e, (c) disseminada em níveis grafitosos. A pirita I tem valores de $\mathrm{Fe}$ de 33,24 a $33,92 \%$ e $\mathrm{S}$ entre 66,04 e 66,75\%. Quando associada à calcopirita, pode apresentar valores mais elevados de Co $(0,13$ a $0,20 \mathrm{ppm})$ e $\mathrm{Ni}(0,14$ a 0,24 ppm), que a pirita I sem calcopirita. A pirita II ocorre em microvênulas monominerálicas na interface de níveis quartzosos e níveis micáceos, ou nos limites dos porfiroblastos de estaurolita nos filonitos (Fig. 10). A pirita II tem Fe entre 33,22 e 33,59\% e $\mathrm{S}$ entre 66,33 e $66,75 \%$. A calcopirita apresenta valores de $\mathrm{Cu}$ entre 24,78 e 25,08\%; Fe entre 24,47 e 24,84\%; Ni até 0,04 ppm e Co entre 0,02 e $0,06 \mathrm{ppm}$.

Nos veios de quartzo mineralizados, ocorrem pirita e ouro, em planos de fraturas e em níveis paralelos ao estiramento do quartzo. $\mathrm{O}$ ouro também ocorre na forma livre, disseminado no quartzo, sem controle microestrutural aparente. Neste caso, os tamanhos de grâo variam entre 1 e $5 \mathrm{~mm}$. O ouro apresenta zonação composicional, marcada por manchas irregulares de prata. Nos veios de quartzo, o ouro apresenta teores entre 86 e 90 ppm e entre 8,68 e 12,77 ppm de prata.

DISCUSSÃO O termo "metamorfismo-hidrotermal" é muito controverso na literatura geoquímica, pois engloba dois processos de alteração: alteração hidrotermal, envolvendo mudanças mineralógicas e químicas a partir de interação fluido-rocha (Velde, 1985) e metamorfismo dinâmico. Em zonas de cisalhamento dúcteis, as transformações mineralógicas ocorridas reúnem características de ambos os processos. Na falta de um termo para melhor conceituar esses processos, o termo "metamorfismohidrotermal", é aqui utilizado para a alteração controlada por tensão cisalhante e pressão de fluidos, conforme sugerido por Shelley (1993). Os conceitos de fácies e zona de metamorfismo são aqui emprestados dos estudos de metamorfismo regional, ou Barroviano. No entanto, uma representação mais completa de

Tabela 4-Resultados das análises químicas (peso \%) por microssonda eletrônica de turmalina de filonitos da ZCC. Símbolos (Nc) núcleo do grão e (Bd) borda.

\begin{tabular}{|c|c|c|c|c|c|c|c|c|c|c|c|c|c|c|c|c|c|c|c|c|c|c|}
\hline \multirow[b]{3}{*}{ Grão } & \multicolumn{5}{|c|}{ Prg-est filonito } & \multirow{2}{*}{\multicolumn{6}{|c|}{$\begin{array}{l}\text { Feg-grn filonito } \\
\text { Nível de quartzo }\end{array}$}} & \multicolumn{11}{|c|}{ Fengita filonito } \\
\hline & \multirow{2}{*}{$\frac{\text { Est. }}{16}$} & \multicolumn{4}{|c|}{ Nível Mb e qzo } & & & & & & & \multicolumn{3}{|c|}{ Nível carb. } & \multirow[b]{2}{*}{$3 n !$} & \multirow[b]{2}{*}{$3 \mathrm{bd}$} & \multicolumn{4}{|c|}{ Nível grafitoso } & \multirow[b]{2}{*}{$12 n !$} & \multirow[b]{2}{*}{$12 b d$} \\
\hline & & $\ln 1$ & lbd & $2 \mathrm{nl}$ & $2 \mathrm{bd}$ & $5 n !$ & $5 b d$ & $6 \mathrm{nl}$ & $6 \mathrm{bd}$ & $8 \mathrm{nl}$ & $8 \mathbf{b d}$ & 14 & 15 & 13 & & & $4 \mathrm{nl}$ & $4 \mathrm{bd}$ & $10 \mathrm{nl}$ & $10 \mathrm{bd}$ & & \\
\hline $\mathrm{SiO}_{2}$ & 36,7 & 36.3 & 36,4 & 35,2 & 36,1 & 35,7 & 36,0 & 36,1 & 36,0 & 35,6 & 36,1 & 36,3 & 35,8 & 36,7 & 35,9 & 35,7 & 35,9 & 36,1 & 36,2 & 35,9 & 36,0 & 36,5 \\
\hline $\mathrm{TiO}_{2}$ & 0,54 & 0,30 & 0,41 & 1,09 & 0,80 & 1,13 & 0,71 & 0,16 & 0,76 & 1,23 & 0,74 & 0,77 & 0,45 & 0,44 & 1,59 & 0,81 & 1,04 & 0,79 & 0,78 & 0,76 & 0,71 & 0,76 \\
\hline $\mathrm{Al}_{2} \mathrm{O}_{3}$ & 34,5 & 33,0 & 34,7 & 31,1 & 33,9 & 31,2 & 33,9 & 35,5 & 34,0 & 30,7 & 33,1 & 33,4 & 33,3 & 34,4 & 30,8 & 33,9 & 31,7 & 33,2 & 32,3 & 34,0 & 31,7 & 33,1 \\
\hline $\mathrm{FeO}$ & 6,40 & 7,66 & 5,93 & 8,47 & 6,13 & 8,81 & 6,30 & 8,87 & 6,44 & 8,26 & 6,13 & 7,14 & 7,99 & 6,63 & 8,79 & 6,25 & 8,07 & 6,21 & 8,13 & 6,47 & 7,95 & 6,54 \\
\hline $\mathrm{MgO}$ & 6,37 & 6,21 & 6,47 & 6,47 & 6,67 & 6,22 & 6,69 & 3,68 & 6,59 & 6,53 & 6,74 & 6,64 & 5,54 & 6,74 & 6,14 & 6,53 & 6,39 & 6,68 & 6,38 & 6,67 & 6,49 & 6,67 \\
\hline $\mathrm{CaO}$ & 0,68 & 0,12 & 0,57 & 0,89 & 0,56 & 0,47 & 0,53 & 0,07 & 0,59 & 0,71 & 0,52 & 0,94 & 0,51 & 0,63 & 0,38 & 0,53 & 0,68 & 0,41 & 0,53 & 0,50 & 0,61 & 0,41 \\
\hline $\mathrm{Na}_{2} \mathrm{O}$ & 2,02 & 2,19 & 1,91 & 2,08 & 1,96 & 2,29 & 2,06 & 1,68 & 2,02 & 2,21 & 2,22 & 1,80 & 2,21 & 1,94 & 2,29 & 2,07 & 2,14 & 2,17 & 2,31 & 2,08 & 2,26 & 2,14 \\
\hline Total & 87,4 & 85,9 & 86,5 & 85,5 & 86,1 & 86,0 & 86,2 & 86,1 & 86,5 & 85,4 & 85,7 & 87,2 & 86,0 & 87,6 & 85,9 & 85,9 & 86,1 & 85,7 & 86,8 & 86,4 & 85,8 & 86,3 \\
\hline \multicolumn{23}{|c|}{ Fórmula estrutural com base em 31 oxigênios } \\
\hline $\mathrm{Si}$ & 7,45 & 7,54 & 7,43 & 7,43 & 7,41 & 7,49 & 7,39 & 7,47 & 7,38 & 7,51 & 7,47 & 7,43 & 7,46 & 7,44 & 7,53 & 7,37 & 7,50 & 7,47 & 7,49 & 7,37 & 7,53 & 7,52 \\
\hline Al & 8,24 & 8,06 & 8,36 & 7,75 & 8,20 & 7,72 & 8,22 & 8,65 & 8,22 & 7,64 & 8,08 & 8,06 & 8,17 & 8,21 & 7,62 & 8,25 & 7,79 & 8,09 & 7,87 & 8,23 & 7,80 & 8,03 \\
\hline $\mathrm{Fe}(\mathrm{t})$ & 1,09 & 1,33 & 1,01 & 1,50 & 1,05 & 1,55 & 1,08 & 1,53 & 1,11 & 1,46 & 1,06 & 1,22 & 1,39 & 1,12 & 1,54 & 1,08 & {$[, 41$} & 1,07 & 1,41 & 1,11 & 1,39 & 1,13 \\
\hline $\mathrm{Mg}$ & 1,93 & 1,92 & 1,97 & 2,04 & 2,04 & 1,95 & 2,05 & 1,13 & 2,02 & 2,05 & 2,08 & 2,03 & 1,72 & 2,03 & 1,92 & 2,01 & 1,99 & 2,06 & 1,97 & 2,04 & 2,02 & 2,05 \\
\hline $\mathrm{Ti}$ & 0,08 & 0,05 & 0,06 & 0,17 & 0,12 & 0,18 & 0,11 & $\mathrm{Nd}$ & 0,12 & 0,20 & 0,12 & 0,12 & 0,07 & 0,07 & 0,25 & 0,13 & 0,16 & 0,12 & 0,12 & 0,12 & 0,11 & 0,12 \\
\hline $\mathrm{Ca}$ & 0,15 & nd & 0,12 & 0,20 & 0,12 & 0,11 & 0,12 & $\mathrm{Nd}$ & 0,13 & 0,16 & 0,12 & 0,21 & 0,11 & 0,14 & 0,09 & 0,12 & 0,15 & 0,09 & 0,12 & 0,11 & 0,14 & 0,09 \\
\hline $\mathrm{Na}$ & 0,79 & 0,88 & 0,76 & 0,85 & 0,78 & 0,93 & 0,82 & 0,67 & 0,80 & 0,90 & 0,89 & 0,71 & 0,89 & 0,76 & 0,93 & 0,83 & 0,87 & 0,87 & 0,93 & 0,83 & 0,92 & 0,85 \\
\hline
\end{tabular}


fácies metamórfica deveria envolver informações detalhadas da composição dos fluidos e da atividade dos seus principais constituintes. A presença de uma fase fluida aquosa no metamorfismo é crítica na velocidade das reações químicas e transporte químico (Bucher \& Frey 1994). Por isso, sugere-se o termo "similar" as condições metamórficas regionais, pois as condições de temperatura podem ser similares, mas as condições de pressão de fluidos são normalmente bem superiores, principalmente quando a razão fluido-rocha é alta.

O termo filonito é aqui utilizado para rochas geradas em zonas de cisalhamento dúcteis por mecanismos de solução por pressão e recristalização. Os filonitos estão incluídos na classificação de Sibson (1977) como milonitos hidratados, ricos em mica, produzidos por efeitos combinados de redução de tamanho de grão e metassomatismo. Acredita-se que os filonitos marquem, possivelmente, locais preferenciais onde a pressão de fluidos é igual ou maior a pressão litostática nas zonas de cisalhamento. Nessas condições, os fluidos governam a reologia da rocha e a deformação, acompanhada de hidrotermalismo, possibilita a formação de um bandamento hidrotermal composicional. Neste sentido, zonas de filonitos podem ser bons guias prospectivos de depósitos minerais hidrotermais, pois a presença dos filonitos implica em intensa percolação de fluidos nessas estruturas.

No caso da Zona de Cisalhamento Cachimbo, foi possível acompanhar a evolução do cisalhamento e alteração metamórfico-hidrotermal a partir do protólito granítico, Suite Manduca, até o grafita filonito e os veios de quartzo auríferos.

O primeiro estágio é marcado por uma intensa alteração filica e milonitização, que gera milonitos precoces compostos por porfiroclastos de feldspato potássico e uma matriz de muscovitaferrifengita, clorita e trilhas de monazita e zircão. A partir dos milonitos, formam-se extensas faixas de filonitos individualizados em: fengita-granada filonito e paragonita-estaurolita filonito. Ambos evoluem para o fengita filonito, com uma paragênese bem mais simples de muscovita-fengita e clorita. Posteriormente, são afetados, por carbonatação e sulfetação, marcadas por vênulas de calcita; vênulas de calcita-pirita-calcopirita; e vênulas monominerálicas de pirita. $\mathrm{O}$ último estágio de alteração metamórficohidrotermal é marcado por grafitização-sulfetação e silicificação. Ocorre a formação do grafita filonito com sulfetos e ouro, que alojam o sistema de veios de quartzo \pm grafita auríferos.

Pela ausência de datações mais precisas do Lineamento Transbrasiliano, duas hipóteses podem ser consideradas: $\left(1^{a}\right)$ o evento tectono-metamórfico de fácies granulito $(2,1 \mathrm{Ga}$; Gorayeb et al. 2000), que afetou as rochas encaixantes, Complexo Porto Nacional e Suite Manduca, é diferente do evento que gerou o grande sistema de cisalhamento do Lineamento Transbrasiliano; $\left(2^{a}\right)$ o sistema de cisalhamento é uma evolução do mesmo evento tectono- metamórfico de fácies granulito. Resultados geocronológicos (Mesquita et al. em preparação) indicam que uma evolução progressiva entre os dois eventos pode ser considerada. Neste sentido, o mesmo evento metamórfico regional de fácies granulito evolui para um evento metamórfico-hidrotermal retrogressivo na $\mathrm{ZCC}$.

Os minerais índices utilizados para determinação do grau do metamorfismo-hidrotermal são granada e estaurolita (Bucher \& Frey 1994) e grafita (Pasteris \& Wopenka 1991, Wopenka \& Pasteris 1993), indicando condições "similares" à fácies anfibolito, zona da estaurolita para a ZCC. Os geotermômetros da clorita, a paragonita e a turmalina são igualmente discutidos.

Como os milonitos precoces não têm minerais índices que definam metamorfismo, os fengita-granada filonito e paragonita-estaurolita filonito são a seguir discutidos. Acredita-se que esses dois filonitos ocorram sincronicamente, como uma partição do metamorfismo-hidrotermal, pois as faixas dos fengita-granada filonito e paragonita-estaurolita filonito ocorrem intercaladas estruturalmente. Neste sentido, a alteração metamórfico-hidrotermal é seletiva, resultando em porções relativamente mais enriquecidas em potássio e magnésio, fengitagranada filonito, e porções relativamente mais enriquecidas em alumínio, paragonita-estaurolita filonito. A paragênese principal do fengita-granada filonito é clorita (porfiroblastos)-muscovita/ fengita-quartzo-granada almandina-turmalina e do paragonitaestaurolita filonito é quartzo-clorita férrica (porfiroblastos)-paragonita-estaurolita-turmalina \pm granada almandina e traços de calcita (tabela 1).

Porfiroblastos Os principais porfiroblastos nos filonitos são estaurolita ( \pm granada almandina) e clorita férrica no paragonita-estaurolita filonito e granada e clorita magnesiana no fengitagranada filonito.

A estaurolita ocorre como porfiroblastos sin-cinemáticos à foliação milonítica $S_{n+2}$, nos filonitos. As evidências apontadas são as relações entre porfiroblasto e foliação $S_{n+2}$ (Fig. 10) e a presença de inclusões de turmalina invariavelmente orientadas segundo $\mathrm{S}_{\mathrm{n}+2}$. A granada ocorre como inclusão em estaurolita ou agregada em níveis na matriz.

Os padrões de inclusão em porfiroblastos podem mimetizar a estrutura da rocha na época do seu crescimento e permite a reconstrução das condições metamórficas de formação do mineral (Paschier \& Trouw 2005). Como as inclusões de turmalina não são helicoidais, os porfiroblastos de estaurolita devem ter se formado relativamente tardios à foliação nos filonitos, pois não sofreram rotações consideráveis.

O principal processo de crescimento dos porfiroblastos é a difusão, tanto em estado sólido como por fluido. $O$ fato dos porfiroblastos de estaurolita serem muito grandes implica em que a taxa de nucleação seja pequena e a taxa de crescimento grande (Vernon, 2004). Poucos sítios de nucleação de estaurolita devem ter se formado para que os porfiroblastos sejam isolados e grandes. No caso da clorita, deve ter ocorrido o contrário, pois os porfiroblastos são muito menores (Fig. 7b e 10) e em maior quantidade.

A abundância de inclusões em porfiroblastos alumino-silicatados é atribuída à mobilidade limitada dos íons de Al. Em condições de fácies anfibolito, íons de $\mathrm{Al}$ são menos móveis que fons de $\mathrm{Si}, \mathrm{Fe}, \mathrm{Mg}, \mathrm{K}$ ou $\mathrm{Ca}$ (Paschier \& Trouw 2005). A estaurolita e a granada devem ter crescido em sítios ricos em $\mathrm{Al}$ nos filonitos da ZCC, como camadas de micas ou porções relativamente mais aluminosas como o paragonita-estaurolita filonito. A dificuldade de substituir minerais sem Al, leva estes a serem inclusos nos porfiroblastos, como a turmalina.

Condições de formação da estaurolita e da granada Apesar de não se encontrar referencias de ocorrências de estaurolita hidrotermal em depósitos de ouro na bibliografia especializada (Hagemann \& Brown 2000, John Ridley informação verbal em outubro de 2005), outros minerais alumino-silicatados são encontrados em halos hidrotermais. Um exemplo é a cordierita e a andalusita, descritas no depósito Transvaal, Austrália (Hagemann et al. 1998). Um outro exemplo é a presença de cordierita e silimanita no depósito Big Bell, Austrália (Phillips \& de Nooy 1988).

A primeira ocorrência de estaurolita marca a transição da fácies xisto verde à fácies anfibolito, em metapelitos. A temperatura da fácies anfibolito inferior é levemente superior a $500^{\circ} \mathrm{C} \mathrm{(cf.}$ Bucher \& Frey 1994). O par estaurolita-granada almandina é um dos pares característicos do fácies anfibolito inferior e médio $\left(550^{\circ} \mathrm{C}\right)$. O campo de estabilidade da estaurolita, com saturação de quartzo e água, tem seu mais amplo intervalo de temperatura, entre $510^{\circ}$ a $670^{\circ} \mathrm{C}$, a pressões de $7 \mathrm{kbar}$. O campo é mais restrito, entre $510^{\circ}$ e $600^{\circ} \mathrm{C}$, para pressões que podem variar de 3 a $12 \mathrm{Kbar}$ (figura 7.3 de Bucher \& Frey 1994). A mica branca paragonita está presente em um grande intervalo do campo de 
estabilidade do par estaurolita-quartzo, até $620^{\circ} \mathrm{C}$ (figura 7.4 de Bucher \& Frey, op.cit.).

Devido à alta pressão de fluidos existente nessas zonas de cisalhamento, é difícil definir a pressão litostática. Contudo conforme Bucher \& Frey (1994), a estaurolita não é estável em metamorfismo de pressões inferiores a $3 \mathrm{kbar}$.

No caso dos porfiroblastos de clorita (estratificados clorita-muscovita) terem se formado as expensas da biotita, como descrito anteriormente, a biotita (especulativamente, e não a clorita) faria parte da paragênese com a estaurolita. O par estaurolita-biotita forma-se a partir da reação granada+clorita, a $600^{\circ} \mathrm{C}$ (Bucher \& Frey 1994). No entanto, como não se obteve análises químicas de biotita, não se tem indícios de que a temperatura tenha atingido $600^{\circ} \mathrm{C}$, e nem foi possível utilizar o geotermômetro biotita-granada.

No caso de não haver biotita na rocha, a decomposição da clorita em rochas com quartzo $\left( \pm 540^{\circ} \mathrm{C}\right)$, depende da fugacidade de oxigênio, para formar o par granada-magnetita (Bucher \& Frey 1994). No caso dos filonitos de Porto Nacional, não se observa magnetita, podendo indicar que a fugacidade de oxigênio não tenha atingido os valores do tampão QFM. Outra possibilidade a ser considerada é de que a temperatura de decomposição da clorita $\left(540^{\circ} \mathrm{C}\right)$ não tenha sido atingida. No entanto, o par estaurolita-granada evidencia mais altas temperaturas.

Condições de formação da clorita e da mica branca A geotermometria da clorita deve ser usada com muito cuidado e somente em conjunto com outros métodos alternativos de estimativa de paleo-temperatura (Caritat et al. 1993), pois os estudos são realizados em rochas com temperaturas inferiores a $350^{\circ} \mathrm{C}$. Os geotermômetros utilizados são Cathelineu (1988, modificado de Cathelineu \& Nieva 1985), que relaciona o aumento de $\mathrm{Al}^{\text {iv }}$ com aumento de temperatura, e Jowett (1991), que modifica o primeiro introduzindo a variável $\mathrm{Fe} /(\mathrm{Fe}+\mathrm{Mg})$ para cloritas com esta razão inferior a 0,6 e temperaturas entre $150^{\circ}-325^{\circ} \mathrm{C}$.

Os resultados de temperatura para as cloritas da Zona de Cisalhamento Cachimbo estão entre $300^{\circ}$ e $400^{\circ} \mathrm{C}$ (tabela 3). Segundo o geotermômetro de Jowett (1991), a clorita no metagranito tem temperaturas de formação entre $282^{\circ}$ e $388^{\circ} \mathrm{C}$. No paragonita-estaurolita filonito, as temperaturas de formação estão entre $336^{\circ}$ e $398^{\circ} \mathrm{C}$; e no fengita-granada filonito as temperaturas de formação nos porfiroblastos entre $318^{\circ}$ e $322^{\circ} \mathrm{C}$; e na matriz entre 316 e $408^{\circ} \mathrm{C}$. Na matriz do fengita filonito, a clorita tem temperatura de formação $350^{\circ} \mathrm{C}$; como produto de alteração de granada entre $374^{\circ}$ e $395^{\circ} \mathrm{C}$; e como produto de alteração de estaurolita entre $326^{\circ}$ e $331^{\circ} \mathrm{C}$; e nas vênulas posteriores entre $385^{\circ}$ e $388^{\circ} \mathrm{C}$. Apesar das análises escolhidas terem razão $\mathrm{Fe} /(\mathrm{Fe}+\mathrm{Mg})$ até 0,6 , os resultados apresentam incongruências como a clorita em equilíbrio com estaurolita ter temperatura menor que a clorita de produto de alteração da estaurolita. Uma possibilidade é que os valores de temperatura mais baixos da clorita, na rocha encaixante e porfiroblastos, podem estar relacionados à presença dos estratificados clorita-muscovita, associados provavelmente às transformações a partir de biotita (identificada opticamente e descrita anteriormente), como o grão 2 nos granitos (tabela 3). Outra possibilidade é que nos filonitos mais aluminosos (paragonita-estaurolita filonito), as variações de $\mathrm{Al}^{\text {iv }}$ não correspondam a variações de temperatura, como em um grão de clorita, produto de alteração da estaurolita, que tem temperatura de $614^{\circ} \mathrm{C}$, pois o $\mathrm{Al}^{\mathrm{iv}}$ é muito alto 4,04 . Caritat et al. (1993) salienta que para intervalos de temperatura superiores a $200^{\circ} \mathrm{C}$ os geotermômetros da clorita tendem a subestimar grosseiramente a temperatura de formação deste mineral em até $150^{\circ} \mathrm{C}$. De um modo geral, a temperatura se mantém aproximadamente constante ao longo do intervalo de evolução da zona Cachimbo. Segundo Bucher \& Frey (1994), a clorita magnesiana pode continuar estável, em rochas com quartzo e muscovita, até $650^{\circ} \mathrm{C}$.

Relacionando os diagramas das figuras 4 e 9, verifica-se três trends positivos para clorita e mica branca: (a) a clorita e a mica branca dos metagranitos apresentam composições férricas e a mica branca I e II desenvolvem um trend entre os termos muscovita e ferri-fengita com os valores mais altos de $\mathrm{Al}^{\mathrm{iv}}$. Nos milonitos precoces, a mica branca, invariavelmente zonada, apresenta o mesmo trend de variação entre muscovita e ferri-fengita; (b) no paragonita-estaurolita filonito, a clorita, em equilíbrio com paragonita, estaurolita e turmalina, apresenta os valores mais elevados de $\mathrm{Fe} \mathrm{e} \mathrm{Al}^{\text {iv }}$, caracterizando um ambiente relativamente mais aluminoso; (c) sincronicamente ocorre o fengita-granada filonito, onde a clorita tem valores mais elevados de $\mathrm{Mg}$, que as rochas anteriores, e a mica branca varia entre os termos muscovita e fengita. A clorita e a mica branca no fengita filonito apresentam as composições mais magnesianas.

A relação entre as rochas menos deformadas (metagranitos) e as mais filonitizadas (fengita filonitos), próximas da mineralização, aponta um acréscimo no conteúdo de magnésio (Fig. 9) contudo as vênulas de clorita posteriores têm valores altos de ferro e $\mathrm{Al}_{(\mathrm{T})}$. A grande heterogeneidade composicional tanto da clorita como da mica branca, nas rochas estudadas, evidencia a formação destes minerais em ambiente hidrotermal provavelmente não tamponado, podendo indicar igualmente que os principais processos de deformação foram deslizamentos intercristalinos e dissolução por pressão (pressure solution) em estado de desequilíbrio. Velde (1991) salienta a importância de longos períodos de duração do processo de difusão para a homogeneidade composicional da clorita (estudo realizado em clorita diagenética), o que não ocorre em alteração hidrotermal.

Ambiente de formação da turmalina A turmalina é um importante mineral hidratado de boro, que ocorre como uma fase acessória em rochas ígneas, metamórficas e hidrotermais. Tem um intervalo de estabilidade grande, da diagênese a fácies granulito (Kawakami 2001). A desestabilização da turmalina ocorre entre $620^{\circ}$ e $650^{\circ} \mathrm{C}$, coincidindo com o decréscimo de boro em rocha total, estudado em Maine e Kodiak-Valdez, Alaska (Moran et al. 1992). O boro nos fluidos tem um papel importante em abaixar a temperatura solidus e a viscosidade das fusões em terrenos granulíticos-migmatíticos (Kawakami 2001), e a atividade do boro nos fluidos é fortemente controlada pela estabilidade da turmalina. Na Zona de Cisalhamento Cachimbo, a turmalina ocorre nos filonitos e as zonações químicas refletem as mudanças ambientais ao longo da evolução desta.

O diagrama de Henry \& Guidotti (1985, Fig. 12) é aqui utilizado no sentido de fornecer informações quanto às condições físico-químicas em que se formou a turmalina. No entanto, os próprios autores salientam que os campos determinados para os diferentes litotipos não são sistemáticos para rochas hidrotermalizadas. Portanto, não foram utilizados para definir tipo de rocha. Conforme Figura 12, o núcleo da turmalina tipo 1 tem um enriquecimento relativo em $\mathrm{Fe}$ e $\mathrm{Al}$, tendendo ao campo dos granitos (campos 1 e 2), enquanto o núcleo da turmalina tipo 2 é relativamente empobrecido em $\mathrm{Al}$ e tende a se concentrar no campo (5) de rochas que não contém fase saturada em alumínio. A diferença composicional entre os grãos de turmalina tipo $1 \mathrm{e}$ 2 sugere que eles se originaram em condições ambientais diferentes. Contudo, há uma similaridade química nas bordas tanto da turmalina tipo 1 como da tipo 2 , sugerindo que as bordas dos dois tipos podem ter sido formadas sob condições físico-químicas análogas, no campo de rochas que coexistem com fases saturadas em alumínio. A composição nas bordas das turmalinas tipo 1 e tipo 2 mostra um aumento relativo de magnésio, o que pode especulativamente refletir a composição dos minerais em 
equilibrio com a turmalina, como muscovita-fengita e clorita re-lativamente mais magnesiana no fengita filonito.

\section{Geotermometria e ambiente de formação do grafita}

espectro estudado do grafita na ZCC é compatível com o espectro de grafita de metamorfismo de fácies anfibolito, zona da estaurolita, conforme, Pasteris \& Wopenka (1991) e Wopenka \& Pasteris (1993), e o valor de $\mathrm{R}^{2}$ compatível com temperaturas de $500^{\circ}$ a $550^{\circ} \mathrm{C}$ (cf. Beyssac et al. 2002).

O grafita está em equilíbrio com quartzo nos veios mineralizados, indicando que a $Z C C$ manteve as condições de temperatura ao longo de sua evolução. Os resultados obtidos em grafita corroboram os dados da análise estrutural e cinemática, que indicam que a formação do sistema de veios é sincrônica a formação dos filonitos (Mesquita, 1996).

O forte controle da temperatura no grau de cristalinidade do grafita é há muito tempo reconhecido e amplamente utilizado (Tuinstra \& Koening 1970, Grew 1974, Beny-Bassez \& Rouzaud 1985, Pasteris \& Wopenka 1991, Wopenka \& Pasteris 1993, Luque et al. 1998, Pasteris 1999, Beyssac et al. 2002). O geotermômetro da matéria carbonosa combina beneficios de fácil aplicabilidade com o de irreversibilidade da transformação da matéria carbonosa em grafita: este marca o pico de temperatura, em contraste com a termobarometria baseada em assembléia mineral, sujeita a re-equilíbrios durante o retrometamorfismo (Beyssac et al. 2002).

Conforme Pasteris (1999) há basicamente dois tipos geneticamente diferentes de grafita: (1) grafita metamórfico, gerado por metamorfismo de matéria orgânica in situ nos sedimentos e ocorre como flocos dispersos de grafita; e (2) veios de grafita (fluid-deposited graphite) precipitado a partir de fluidos ricos em C-O-H, saturados em grafita. Ocorrem como veio ou pod. Só recentemente o grafita hidrotermal tem sido reconhecido como um tipo distinto (Pasteris op. cit.).

O grafita estudado ocorre em veios de quartzo ou substituindo filossilicatos e carbonato nos filonitos, sendo caracterizado como do tipo 2, depositado a partir de fluidos ricos em G-C-O-H (G para grafita).

A temperatura é o fator principal na formação de veios de grafita. Esta controla não só o estado de saturação do grafita no fluido aquoso e a espécie de carbono no fluido carbônico, como o grau de cristalinidade do grafita que precipita de um desses fluidos (Pasteris 1999). A precipitação de grafita de alta cristalinidade demanda a disponibilidade de fluidos de alta temperatura.

Com base na temperatura obtida pela alta cristalinidade do grafita estudado, é possível estimar a fugacidade de oxigênio $\left(f \mathrm{O}_{2}\right)$ de precipitação deste a partir de um fluido rico em G-C$\mathrm{O}-\mathrm{H}$, conforme Connolly \& Cesare (1993). A $\mathrm{fO}_{2}$ estimada é de $10^{-24}$ a $500^{\circ} \mathrm{C}$ a $10^{-22}$ a $550^{\circ} \mathrm{C}$.

Ambiente de formação dos sulfetos e mecanismos de precipitação do grafita e ouro A paragênese grafita, quartzo, pirita e calcopirita caracteriza o grafita filonito.

A pirita, a baixas pressões, tem a estabilidade termal máxima a $742^{\circ} \mathrm{C}\left( \pm 1^{\circ} \mathrm{C}\right)$ no sistema Fe-S (Vaughan \& Craig 1997). Conforme os mesmos autores, no sistema $\mathrm{CuFe}-\mathrm{S}$, o par piritacalcopirita é estável até $550^{\circ} \mathrm{C}$ a uma atividade de enxofre $\left(a \mathrm{~S}_{2}\right)$ de $10^{-6}$ a $10^{-11}$.

O ouro ocorre invariavelmente disseminado nas faixas ricas em grafita, tanto do grafita filonito como dos veios de quartzo.

$\mathrm{O}$ grafita precipita a partir de fluidos de alta temperatura, ricos em $\mathrm{C}-\mathrm{O}-\mathrm{H}$, quando a sua composição entra no campo de estabilidade do grafita e o fluido atinge a saturação. Os principais mecanismos de formação do grafita são: (a) variações de temperatura, (b) descompressão em zonas de falha, (c) mudanças na composição do sistema levando igualmente a saturação do grafita (Pasteris 1999).

As mudanças podem ocorrer principalmente por reações de hidratação, variações nas condições de fugacidade de oxigênio, ou mistura de diferentes fluidos contendo carbono (French 1966, Frost 1979, Connolly \& Cesare 1993, Luque et al. 1998).

Os dados obtidos, somados aos estudos realizados em inclusões fluidas (Mesquita et al. a em preparação) permitem uma discussão das diversas possibilidades, tanto de precipitação do grafita como do ouro:

- no grafita filonito, mudanças na granulação e textura da rocha, próprias da milonitização e processos de strain softening (Pasteris \& Wopenka 1991), podem ter levado a substituição pervasiva de carbonato e filossilicatos em grafita;

- as reações de hidratação podem ser consideradas importantes na formação do grafita e do ouro nos veios de quartzo. Dois tipos de inclusões foram identificadas nos mesmos sítios estruturais em quartzo, o tipo $\mathrm{AC}$ contendo $\mathrm{H}_{2} \mathrm{O}-\mathrm{CO}_{2}$ e baixa salinidade e o tipo A contendo $\mathrm{H}_{2} \mathrm{O}$ e salinidades variadas. A mistura destes dois fluidos seria um fator importante no abaixamento de temperatura e precipitação de grafita e ouro. Conforme Pasteris (1999), a altas temperaturas, um pequeno abaixamento de temperatura, na ordem de $50^{\circ} \mathrm{C}$, pode levar a precipitação de grafita;

- a ausência de evidências de efervescência (boiling) nas inclusões fluidas estudadas (Mesquita et al. a em preparação), a descompressão em zonas de falha não é apontada como um processo efetivo de precipitação do ouro na ZCC.

Estudos mais aprofundados são sugeridos para melhor compreender as relações genéticas entre a formação de grafita e precipitação do ouro. Conforme Maynard (1983), o grafita pode ter exercer uma atividade catalizadora nas reações de precipitação do ouro.

CONCLUSÕES A Zona de Cisalhamento Cachimbo (ZCC) faz parte do sistema de cisalhamento transcorrente do Lineamento Transbrasiliano. A ZCC é responsável pela formação de milonitos e filonitos que alojam um complexo sistema de veios de quartzo, mineralizados a ouro. As rochas encaixantes são metagranitos de fácies anfibolito superior a granulito, pertencentes provavelmente ao Arco magmático de Goiás, Província Tectônica do Tocantins.

A partir de evidências de química mineral e microestruturas foi possível caracterizar e discutir as condições físico-químicas do cisalhamento, metamorfismo-hidrotermal, interação fluido-rocha e mineralização da ZCC. O primeiro estágio de milonitização é marcado por uma intensa alteração filica, que gera milonitos precoces com porfiroclastos de feldspato envoltos por uma matriz com quartzo, muscovita-ferrifengita, clorita, monazita e zircão.

A partição do metamorfismo-hidrotermal gera dois tipos de filonitos identificados de acordo com a variedade de mica branca presente: (a) fengita-granada filonito, com a paragênese quartzogranada-clorita-muscovita/fengita-turmalina e, (b) paragonitaestaurolita filonito com a paragênese quartzo-clorita-paragonitaestaurolita-turmalina \pm granada \pm calcita. Os paragonita-estaurolita filonitos caracterizam sítios relativamente mais aluminosos e os fengita-granada filonitos caracterizam sítios relativamente mais magnesiano. A orientação concordante com a foliação da matriz de inclusões de turmalina em porfiroblastos de estaurolita e a relação porfiroblasto-foliação, caracterizam os porfiroblastos como sin-cinemáticos a foliação principal dos filonitos (Paschier \& trouw 2005).

A formação de estaurolita e granada indica condições similares de metamorfismo-hidrotermal de fácies anfibolito, zona da estaurolita, entre $500^{\circ}$ e $550^{\circ} \mathrm{C}$ e pressões mínimas de $3 \mathrm{kbar}$, pois é a pressão mínima de estabilidade da estaurolita (conforme Bucher \& Frey 1994).

Acredita-se que a temperatura de formação da clorita entre 
$300^{\circ}$ e $400^{\circ} \mathrm{C}$, seja subestimada, pois como abordado por Caritat et al. (1993) é o que se observa para temperaturas de formação de clorita acima de $200^{\circ} \mathrm{C}$. Além do mais, nos filonitos mais aluminosos é possível que as variações de $\mathrm{Al}^{\mathrm{iv}}$ não correspondam a variações de temperatura.

Os paragonita-estaurolita filonito e os fengita-granada filonito evoluem para o fengita filonito, caracterizado pela substituição de estaurolita e granada pela muscovita-fengita e pela clorita mais magnesiana e o aparecimento de sulfetos. Vênulas de calcita, calcita-pirita-calcopirita e vênulas monominerálicas de pirita cortam os filonitos.

A zona potencialmente mineralizada é marcada pelo aparecimento de níveis centimétricos de grafita e pirita no fengita filonito, os quais evoluem para o grafita filonito, com a paragênese quartzo-grafita-pirita-calcopiritatouro. $\mathrm{O}$ grafita filonito é invariavelmente encaixante dos veios de quartzo auríferos, que tem a paragênese quartzo-pirita \pm calcopirita \pm grafita \pm ouro.
O fato do grafita de alta cristalinidade estar em equilíbrio com quartzo, nos veios mineralizados, implica em que as condições de fácies anfibolito, zona da estaurolita, tenham se mantido ao longo de todo o período de atuação da Zona de Cisalhamento Cachimbo. Como o grafita ocorre não só nos filonitos como também nos veios, o grafita deve ser do tipo veio (fluid-deposited graphite).

A fugacidade de oxigênio $\left(f \mathrm{O}_{2}\right)$ estimada para a precipitação do grafita estudado é baixa, de $10^{-24}$ a $500^{\circ} \mathrm{C}$ a $10^{-22}$ a $550^{\circ} \mathrm{C}$ (Connolly \& Cesare 1993), caracterizando um ambiente metamórficohidrotermal redutor para as transformações mineralógicas finais na Zona de Cisalhamento Cachimbo e a precipitação do ouro. $\mathrm{O}$ grafita pode ter atuado como catalizador das reações que levaram a precipitação de ouro (Maynard 1983).

Agradecimentos A primeira autora agradece aos órgãos financiadores CNPq e CAPES pelos auxílios durante a realização do Doutorado e Doutorado Sanduíche.

\section{Referências}

Barradas J.A., Lafon J.M., Kotschoubey B. 1992. Geocronologia Pb-Pb e Rb-Sr da região de Monte do Carmo - Porto Nacional, TO. Novos Resultados. In: RBG, Congresso Brasileiro de geologia, 37, Anais 1, p. 182-183.

Barrenchea J.F, Luque, F.J., Rodas, M. \& Pasteris, J.D. 1997. Vein-type graphite in Jurassic volcanic rocks of the external zone of the Betic Cordillera (Southern Spain). Canadian Mineralogist, 35:1379-1390.

Benny-Bassez C. \& Rouzaud J. 1985. Characterization of Carbonaceous materials by correlated electron and optical microscopy and Raman micro spectroscopy. Scanning Electron Microscopy, 1985:119-132.

Bayliss P. 1975. Nomenclature of the trioctahedral chlorites. Canadian Mineralogist, 13:178-180.

Beyssac O., Goffé B., Chopin C., Rouzaud J. 2002. Raman spectra of carbonaceous material in metasediments: a new geothermometer. Journal of Metamorphic Geology, 20:859-871.

Bezerra P.E., Cunha B.C., Ianhez A.C., Potiguar L.A., Pitthan J.H., Souza J.R., Montalvão R.M., Souza, A.M. 1981. Associação plutonovulcânica de Ipueiras. In: SBG, Simpósio de Geologia do CentroOeste, 1, Atas, p. 363-375.

Bitencourt M.F. 1996. Granitóides da região de Porto Belo, SC: uma abordagem petrológica e estrutural do magmatismo em zonas de cisalhamento. Tese de doutoramento, Instituto de Geociências, UFRGS, $310 \mathrm{p}$.

Bryndzia L.T. \& Scott S.D. 1987. The composition of chlorite as a function of sulfur and oxygen fugacity: an experimental study. American Journal of Science, 287:50-76

Bucher K. \& Frey M. (Eds.) 1994. Petrogenesis of Metamorphic rocks. Complete Revision of Winkler's Textbook. Springer-Verlag, Berlin, $318 \mathrm{p}$.

Caritat P., Hutcheon I., Walshe J. 1993. Chlorite geothermometry: a review. Clays and Clay Minerals, 41(2):219-239.

Cathelineau M. 1988. Cation site occupancy in chlorites and illites as a function of temperature. Clay Miner. 23:471-485.

Cathelineau M. \& Nieva D. 1985. A chlorite solid solution geothermometer: The Los Azufres (Mexico) geothermal system. Contrib. Mineral Petrol, 91:235-244.

Connally J.A.D. \& Cesare B. 1998. C-O-H-S .uid composition and oxygen fugacity in graphitic metapelites. Journal of Metamorphic Geology, 11:379-388

Cordani U., Sato K., Teixeira W., Tassinari C.C.G. \& Basei M.A.S. 2000. Crustal Evolution of the South American Platform. In: U.G. Cordani, E. J. Milani, A. Thomaz Filho, D.A. Campos (eds.) Tectonic Evolution of South America, SBG, Rio de Janeiro, pp.: 19-40.

Cox S.F., Etheridge M.A., Wall V.J. 1990. Fluid pressure regimes and fluid dynamics during deformation of low-grade metamorphic terrains implications for the genesis of mesothermal gold deposits. In: F. Robert, P. A. Sheahan, S. B. Green (eds.) Greenstone Gold and Crustal Evolution. NUNA conference, Geological Association of
Canada, pp.: 46-53.

Cunha F.S.S. 1996. Análise estrutural e estatistica de lineamentos aplicada à pesquisa mineral: o caso da Região de porto nacional, TO. Dissertação de mestrado, Escola de Minas - UFRGS, 235p.

Dubessy J. 1984. Simulation of chemical equilibrium in the C-O-H system; methodological consequences for fluid inclusions. Bulletin de Mineralogie, 107:155-168.

Deer W.A., Howie R.A. \& Zussman J. 2002. Introduction to the rockforming minerals. Longman, London, 528p.

Fitz Gerald J.D. \& Stünitz 1993. Deformation of granitoids at low metamorphic grade. I: Reactions and grain size reduction. Tectonophysics, 221:269-297.

Foster M.D. 1962. Interpretation of the composition and a classification of the chlorites. U.S. Geological Survey Prof. Paper, 414(A):A1-A33.

French B.M.1966. Some geological implications of equilibrium between graphite and a $\mathrm{C}-\mathrm{H}-\mathrm{O}$ gas phase at high temperatures and pressures. Reviews in Geophysics, 4:223-253.

Frost B.R 1979. Mineral equilibria involving mixed-volatiles in a C$\mathrm{O}-\mathrm{H}$ fluid phase. The stabilities of graphite and siderite. American Journal of Science, 279:1033-1059.

Goddard J. \& Evans J. 1995. Chemical changes and fluid-rock interaction in faults of crystalline thrust sheets, northwestern Wyoming, USA. Journal of Structural Geology, 17:533-547.

Gomes M.E.B. 1990. Granito Arroio Moinho: Feições de deformação. Acta Geol. Leopoldense, 13:37-54.

Gorayeb P.S.S. 1996. Petrologia e Evolução Crustal das Rochas de Alto Grau de Porto Nacional - TO. Tese de Doutoramento, Centro de Geociências, Universidade Federal do Pará, 261p.

Gorayeb P.S.S., Moura C.A.V. \& Barros G.B. 2000. Pb/Pb zircon ages of the Porto Nacional high grade metamorphic terrain, Northern Portion of the Goias Massif, Central Brazil. Revista Brasileira de Geociências 30:190-194.

Gottardo E. 1996. Alojamento de granitos em zona de cisalhamento e sua relação com os depósitos auriferos em veios da região de Porto Nacional (TO). Dissertação de Mestrado, Escola de Engenharia, UFRGS, Porto Alegre, $120 \mathrm{p}$.

Grew E. 1974. Carbonaceous material in some metamorphic rocks of New England and other areas. Journal of Geology, 82:50-73.

Groves D.I., Goldfarb R.J., Gebre-Mariam M., Hageman S.G. \& Robert F. 1998. Orogenic gold deposits-a proposed classification in the context of their crustal distribution and relationship to other gold deposit types: Geology Reviews, 13:7-27.

Guidotti C.V. 1987. Micas in metamorphic rocks. In: S. W. Bailey (ed.) Micas. Reviews in Mineralogy 13, Mineralogical Society of America, pp.: 357-456.

Hageman S. \& Brown P. (eds.) 2000. Gold in 2000. Reviews in Economic Geology Series 13, SEG, 560 pp.

Hageman S.G., Brown F., Ridley J., Stern P., Fournelle J. 1998. Ore pe- 
trology, chemistry, and timing of electrum in the Archean hypozonal Transvaal lode gold deposit, Western Australia. Economic Geology, 93:271-291.

Hasui Y. \& Haralyi N. 1985. A mega estruturação de Goias. In: SBG, Simpósio de Geologia do Centro-oeste, 1, Anais, v. 1, p. 120-144.

Hasui Y. \& Sena Costa J.B. 1990. O Cinturão Araguaia: um novo enfoque estrutural estratigráfico. In: SBG, Congresso Brasileiro de Geologia, 36, Anais, v. 6, p. 2535-2549.

Hasui Y., Sena Costa J.B. \& Silva J.R. 1984. Província Tocantins - Setor Setentrional. In: F. Almeida \& Y. Hasui (eds). O Pré-Cambriano do Brasil. Edgard Blücher Ltda., pp.: 2205-2264.

Henry D. \& Guidotti C.V. 1985. Tourmaline as a petrogenetic indicator mineral: an example from the staurolite grade metapelites of $\mathrm{NW}$ Maine. American Mineralogist, 70:1-15.

Hippert J.F. 1998. Breakdown of feldspar, volume gain and lateral mass transfer during mylonitization of granitoid in a low metamorphic grade shear zone. Journal of Structural Geology, 20:175-193.

Hirth G. \& Tullis J. 1992. Dislocation creep regimes in quartz aggregates. Journal of Structural Geology, 14:145-159.

Hodgson C.J. 1989. Patterns of mineralization. In: J.T. Bursnall, C.J. Hodgson, C. Hubert, R.W. Kerrich, P. Marquis, J.B. Murphy, I. Osmani, H. Poulsen, F. Robert, M. Sanborn-Barrie, G. Stott \& H.R. Williams (eds.) Mineralization and Shear Zones. Geological Association of Canada Short Course Notes, 6, pp.: 51-84.

Johnson S.E., Fletcher J.M., Fanning C.M., Vernon, R.H., Paterson, S.R., Tate, M.C. 2003. Structure, emplacement and lateral expansion of the San José tonalite pluton Peninsular ranges batholith, Baja California, Mexico. Journal of Structural Geology, 25:1933-1957.

Jowett E.C. 1991. Fitting iron and magnesium into the hydrothermal chlorite geothermometer. In: GAC/MAC/SEG, Joint Annual Meeting. Program with abstract 16, p. A62.

Kawakami T. 2001. Tourmaline breakdown in the migmatite zone of the Ryoke metamorphic belt, SW Japan. Joumal of Metamorpihc Geology, 19:61-75.

Khrull, J.H. 1996. Prism- and basal-plane parallel subgrain boundaries in quartz: a microstructural geothermobarometer. Journal of Metamorphic Geology, 14:581-589.

Large R.R. 1975. Zonation of hydrothermal minerals at the Juno Mine, Tenant Creek Gold.eld, Central Australia. Economic Geology, 70:1387-1413.

Luque F. \& Rodas M. 1999. Constraints on graphite crystallinity in some Spanish fluid-deposited occurrences from different geologic settings. Mineralium Deposita, 34:215-219.

Luque F., Pasteris J., Wopenka B., Rodas M. \& Barrenchea J. 1998. Natural fluid-deposit graphite: mineralogical characteristics and mechanisms of formation. American Journal of Science, 298:471-498.

Marini O, Fuck R., Dardene M. \& Danni J. 1984. Província TocantinsSetores Central e Sudeste. In: F. Almeida \& Y. Hasui (eds). O PréCambriano do Brasil. Edgard Blüncher Ltda., pp.: 2205-2264.

Mathez E.A., Dietrich V.J., Holloway J.R. \& Boudreau A.E. 1989. Carbon distribution in the Stillwater Complex and evolution of vapor during crystallization of Stillwater and Bushveld magmas. Journal of Petrology, 30:153-173.

Mesquita M.J. 1996. Controle estrutural e alteração hidrotermal nos depósitos de ouro da província de Porto Nacional, TO, Brasil. Tese de doutoramento Instituto de Geociências, UFRGS, P, Alegre, 280p.

Mesquita M.J. \& Fernandes L.A.D. 1991. Petrografia dos granitóides deformados na Zona de Cisalhamento Dorsal de Cangucu, Região Quitéria/ Capivarita, RS. Acta Geologica Leopoldense, 30:55-74.

Mesquita M.J., Hartmann L.A., Arpuim A. P., Pereira O.N.G., Gottardo E. 1992. Geologia da Região de Porto Nacional, TO. In: SBG, Congresso Brasileiro de Geologia 37, Anais 2, p. 273-274.

Mesquita M.J., Samson I.M., Longstaffe F.J., Fyfe W.S. \& Hartmann L.A. ( $a$ em preparação). Fluid evolution and shear deformation of vein-type gold deposits, Tocantins tectonic province, Porto Nacional region, Brazil: fluid inclusion and stable isotope evidence.

Mesquita M.J., Hartmann L.A., Orestes, J. ( $b$ em preparação) SHRIMP $\mathrm{U}-\mathrm{Pb}$ zircon ages from Porto Nacional region, Tocantins Tectonic Province.

Mexias A.S., Gomes M.E.B., Mesquita M.J. 1997. Mudanças químicas, mineralógicas e volumétricas relacionadas a processos de deformação nas Zonas de Cisalhamento Mutum e Cachimbo, TO, Brasil. In:
SBGq, X Semana de Geoquímica, 10, \& Congresso de Geoquímica dos Países de Língua Portuguesa, 4, Resumos expandidos, p. 211214.

Moran A., Sisson V. \& Leeman V. 1992. Boron depletion during progressive metamorphism: Implications for subduction process. Earth and Planetary Science Letters, 111:331-349.

Nesbitt B.E. 1982. Metamorphic sulfite-silicate equilibria in the massive sulfite deposits at Ducktown, Tennessee. Economic Geology, 77:364-378.

Paschier C.W. \& Trouw R.A.G. 2005. Microtectonics. 2nd Ed. Springer, $366 \mathrm{p}$.

Pasteris J.D. \& Chou I.M. 1998. Fluid-deposited graphitic inclusions in quartz: comparison between KTB (German Continental DeepDrilling) core samples and artificially re-equilibrated natural inclusions. Geochimica et Cosmochimica Acta, 62:109-122.

Pasteris J. 1999. Causes of uniformly high crystallinity of graphite in large epigenetic deposits. Journal of Metamorphic Geology, 17:779-787.

Pasteris J.D. \& Wopenka B. 1991. Raman spectra of graphite as indicators of degree of metamorphism. Canadian Mineralogist, 29:1-9.

Phillips G.N. \& de Nooy, D. 1988. High grade metamorphic process which influence Archean gold deposits, with particular reference to Big Bell, Australia. Journal Metamorphic Geology, 6:95-114.

Pimentel M.M. \& Fuck R.A. 1992. Neoproterozoic crust accretion in Central Brazil. Geology, 26:519-522.

Poulsen K.H. \& Robert F. 1989. Shear zone and gold: practical examples from southern Canadian shield. In: J.T. Bursnall. (ed.) Mineralization and Shear Zones. GAC, pp.: 234-266.

Schobbenhaus Filho C., Ribeiro C.L., Oliva L.A., Takanohashi J.T., Lindenmayer A.G., Vasconcelos J.C. \& Orlandi V. 1975. Carta Geológica do Brasil ao Milionésimo; Folha Goiás (SD-22). DNPM.

Sena Costa J.B. \& Hasui I. 1988. Aspecto do Lineamento Transbrasiliano na região de Porto Nacional-Natividade, GO. In: SBG, Congresso Brasileiro de Geologia 35, Anais, v. 5, p. 2208-2216.

Sena Costa J.B., Lemos R.L., Martins J.P.A., Beltrão, A.M.G., Hasui, Y. 1984. Geologia da região de Porto Nacional, Go. Revista Brasileira de Geociências, 14(1):3-11.

Shelley D. (ed.) 1993. Igneous and Metamorphic Rocks under the microscope. Chapman \& Hall, London, $445 \mathrm{p}$.

Sibson R.H. 1977. Faults and fault rock mechanism. Bull. Geological Society of London, 133:191-213.

Sibson R.H. 1990. Fault structure and mechanics in relation to greenstone gold deposits, In: F. Robert, P. A. Sheahan, S. B. Green (eds.) Greenstone Gold and Crustal Evolution. NUNA conference, Geological Association of Canada, pp.: 54-60.

Tuinstra F. \& Koening J. 1970. Raman spectrum of graphite. Journal of Chemical Physics, 53:1126-1130.

Tullis J. \& Yund R.A. (1985) Dynamic recrystallization of feldspars: a mechanism for ductile shear zone formation. Geology, 13:238-241.

Tullis J. \& Yund R.A. (1987) Transition from cataclastic flow to dislocation creep of feldspar: mechanisms and microstructures. Geology, 15:606-609.

Vaughan D.J. \& Craig J.R. 1997. Sulfide ore mineral stabilities, morphologies, and intergrowth textures. In: Barnes, H.L. (ed.). Geochemistry of Hydrothermal Ore Deposits. J.Wiley, pp.: 367-434.

Velde B. 1985. Clay minerals. A physico-chemical explanation of their occurrence. In: B. Velde (ed.) Developments in Sedimentology, 40. Elsevier Science Publishers. Amsterdam, pp.: 115-124

Velde B., El Moutaouaki N. \& Lijima A. 1991. Compositional homogeneity in low-temperature chlorites. Contrib. Mineral. Petrol., 107:21-26.

Vernon R.H. (ed.) 2004. A practical guide to rock microstructure. Cambridge University Press, London, $594 \mathrm{p}$.

Wopenka B. \& Pasteris J. 1993. Structural characterization of kerogens to granulite-facies graphite: applicability of Raman microprobe spectroscopy. American Mineralogist, 78:533-557.

Zhang W. \& Fyfe W.S. 1995. Chloritization of the hydrothermally altered bedrock at the Igarapé Bahia gold deposit, Carajás, Brazil. Mineralium Deposita, 30:30-38.

Manuscrito A-1486 Revisão aceita em 18 de agosto de 2006 